\title{
An Overview of the Treatment Efficacy and Side Effect Profile of Pharmacological Therapies in Asian Patients with Breast Cancer
}

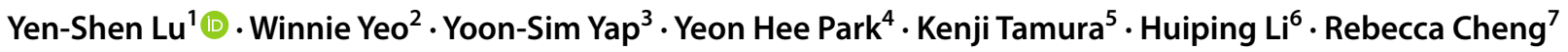

Accepted: 21 August 2021 / Published online: 28 September 2021

(c) The Author(s) 2021

\begin{abstract}
Breast cancer (BC) among Asians accounts for 40\% of the global BC burden. Differences in BC risk, presentation, tumor biology, and response to treatment exist between Asian and non-Asian patients; however, Asian patients are often underrepresented in clinical trials. This narrative review summarizes the efficacy and safety of pharmacological therapies for BC in Asian populations, with a focus on outcomes in Asian versus non-Asian patients treated with chemotherapy, hormone therapy, anti-human epidermal growth factor receptor-2 targeted therapies, cyclin-dependent kinase 4/6 (CDK4/6) inhibitors, mammalian target of rapamycin inhibitors, bone-targeted therapies, poly-ADP ribose polymerase, phosphoinositide 3-kinase, and checkpoint inhibitors. While most therapies have demonstrated comparable efficacy and safety in Asian and non-Asian patients with $\mathrm{BC}$, differences that are largely attributed to pharmacogenetic variations between populations exist. Pharmacogenetic differences may contribute to a reduced clinical benefit of tamoxifen, whereas improved clinical outcomes have been reported with tyrosine kinase inhibitors and CDK4/6 inhibitors in Asian versus non-Asian patients with BC. In particular, Asian patients have an increased incidence of hematological toxicities, including neutropenia, although adverse events can be effectively managed using dose adjustments. Recent trials with CDK4/6 inhibitors have increased efforts to include Asians within study subsets. Future clinical trials enrolling higher numbers of Asian patients, and an increased understanding of differences in patient and tumor genetics between Asians and non-Asians, have the potential to incrementally improve the management of $\mathrm{BC}$ in Asian patients.
\end{abstract}

\section{Key Points}

Data suggest important differences in tumor biology,

Yen-Shen Lu

yslu@ntu.edu.tw

1 Department of Oncology, National Taiwan University Hospital, No. 7, Chung Shan South Road, Taipei 100, Taiwan

2 Department of Clinical Oncology, The Chinese University of Hong Kong, Shatin, Hong Kong

3 Division of Medical Oncology, National Cancer Centre Singapore, Singapore, Singapore

4 Sungkyunkwan University, SKKU-Samsung Medical Centre, Seoul, South Korea

5 Department of Breast and Medical Oncology, National Cancer Center Hospital, Tokyo, Japan

6 Key Laboratory of Carcinogenesis and Translational Research (Ministry of Education/Beijing), Department of Breast Oncology, Peking University Cancer Hospital and Institute, Beijing, China

7 Eli Lilly and Company, Taipei, Taiwan treatment response, and metabolism of anticancer drugs between Asians and non-Asians with breast cancer (BC), yet the majority of clinical trials are conducted in Western settings.

A review of the literature suggests that while many treatments for Asians and non-Asians with $\mathrm{BC}$ often have similar efficacy and safety, important differences have been reported, particularly regarding hematological toxicities.

There is a need for future studies to enroll a higher proportion of Asian patients, and for further research into the reasons behind the differences seen between Asians and non-Asians with $\mathrm{BC}$, in order to improve the management of Asian patients with this disease. 


\section{Introduction}

Breast cancer (BC) in Asian women accounts for $~ 40 \%$ of the global BC incidence [1], and is rising [2-5]. Age-standardized incidence rates in Asia vary considerably across the continent, but are lower than in Western countries. Mortality rates are substantially higher compared with Western populations, although there also are large variations in $\mathrm{BC}$ mortality rates across Asia [1-3]. Furthermore, BC in Asia typically affects a younger population at a more advanced stage $[1,4,5]$.

Patients in Asian and non-Asian countries share several risk factors contributing to $\mathrm{BC}$ development, including early menarche, late menopause, older age at first pregnancy, and absence of breastfeeding $[1,4,5]$. In contrast, dietary and lifestyle factors, including lower alcohol consumption, less hormone replacement therapy, lower body mass index (BMI), and increased consumption of soy-based products reduce the risk of $\mathrm{BC}$ in Asian women [5]. Although an increasingly Westernized lifestyle accounts for rapidly rising BC incidence among East Asian women, a recent study demonstrated significant differences in secular trends with age-specific incidences of female BC in Asians versus a USA-based population [6]. Furthermore, the age-specific pathological features of BC in East Asian countries were distinct from the USA, but similar to Asian Americans, thereby suggesting ethnic differences in its etiology and biology [6].

Genetic differences between Asians and non-Asians may also contribute to differences in tumor biology, response to treatment, and metabolism of anticancer drugs [3-5, 7]. Initial speculations focusing on early onset of BC in Asians suggested a higher frequency of the basal-like subtype $\mathrm{BC}$, characterized by poor differentiation, resulting in a relatively poor prognosis [8, 9]. However, recent studies in Taiwan and Japan indicated that women aged $<50$ years have a higher probability of hormone receptor-positive disease and lower probability of triple-negative $\mathrm{BC}$ than those $\geq 50$ years of age [8-10]. Evidence also suggests that pharmacogenetic differences contribute to chemotherapy having poorer tolerability and higher toxicity among Asians [3]. The majority of clinical trials are conducted in Western settings, limiting the applicability of their data to Asian populations.

In this review, we provide an overview of the efficacy and safety of pharmacological therapies for BC in Asians, with a focus on comparing outcomes in Asian versus non-Asian patients.

\section{Search Strategy}

This article is a narrative review. A series of free-text searches in PubMed for papers published between January 2000 and June 2021 were conducted using various combinations of keywords, including: breast cancer; anastrozole, letrozole, goserelin, tamoxifen, fulvestrant, lapatinib, pertuzumab, neratinib, ribociclib, abemaciclib, palbociclib, everolimus, denosumab, zoledronic acid, talazoparib, veliparib, olaparib, rucaparib, niraparib, Talzenna, AZD-281, MK-7339, Lynparza, pembrolizumab, atezolizumab, tislelizumab, avelumab, durvalumab, alpelisib, BYL719, idelalisib, copanlisib, duvelisib, taselisib, buparlisib, BMK120, and umbralisib; and Asian, Japan, Japanese, China, Chinese, Taiwan, Taiwanese, Korea, Korean, and ethnicity. In addition, a search of key congresses was undertaken, the reference lists of papers found in the search were examined for relevant studies, and key papers were included based on the authors' clinical experience and knowledge of the field.

\section{Chemotherapy}

The efficacy of chemotherapy in Asians is generally comparable to that observed in Caucasians, based on a retrospective comparison of East Asian and global studies using paclitaxel and gemcitabine [11]. Slightly higher response rates (44.6-50.0\% vs. 41.4\%), 12-month overall survival (OS) (78.6-86.5\% vs. 71.1\%), and progression-free survival (PFS) (7.6-7.7 months vs. 5.9 months) were observed in East Asians receiving paclitaxel-gemcitabine therapy for metastatic BC compared with the global population [11]. Of note, these findings are based on a limited number of studies with relatively small sample sizes that were subject to high censoring rates, and the global studies included more patients with worse performance status [11]. Despite this, several differences were observed in the pharmacological properties of chemotherapy in Asians compared with other races. East Asian patients are generally more susceptible to chemotherapeutic side effects compared with patients in Western countries [12]. A larger population of Japanese patients had grade 4 neutropenia with carboplatin-paclitaxel combination therapy, a long-standing doublet regimen that was well tolerated in patients with lung and ovarian cancers in the USA $[13,14]$.

Hematological toxicities are key areas of difference between Asians and other races. Several studies have reported a higher prevalence of neutropenia in Asian versus non-Asian patients administered chemotherapy, despite lower dosage in some Asian countries [11, 15]. For example, $>30 \%$ of Asians treated with four cycles of adjuvant docetaxel-cyclophosphamide experienced grade $\geq 3$ neutropenia compared with $<5 \%$ of Caucasians [16]. Increased hematological toxicity was reported in Asians administered taxane-based therapy $[11,17]$. Notably, increased risk of docetaxel-related hematological adverse events (AEs) is associated with a lower clearance rate of docetaxel in Asians [18]. An increased incidence of edema, myalgia, nail 
disorder, febrile neutropenia, upper respiratory tract infection, reduced appetite, and rash were reported for Asians treated with either trastuzumab or pertuzumab and trastuzumab, in combination with docetaxel [19]. These AEs led to $47 \%$ of docetaxel dose reductions in Asians versus $13 \%$ in non-Asians, though a similar number of treatment cycles were administered in both groups and treatment efficacy was not significantly affected [19]. Cyclophosphamide in combination with doxorubicin was also linked to higher rates of hematological toxicity [20, 21]. In particular, low BMI may be a risk factor for hematological toxicities in Asians, although the risk may be effectively managed using a dose adjustment or titration strategy [20-23]. Potential interactions related to co-exposure with traditional medicine and chemotherapy remain largely unknown [20].

Despite the absence of relevant differences in clinical antitumor activity, regional disparity exists in tolerability profiles and phenotypic characteristics of some cytotoxic agents among Asians and non-Asians [24, 25]. Asians are known to metabolize capecitabine faster than Caucasians, and hence are more likely to tolerate higher doses, without influencing efficacy [26]. Patients from the USA were $~ 3.5$ times more susceptible to developing grades 3 and 4 gastrointestinal toxicities compared with Asians when receiving fluoropyrimidine treatment [24]. In contrast, no clinically relevant differences in pharmacokinetics, efficacy, or safety were observed with gemcitabine, paclitaxel, or vinorelbine $[11,23,27,28]$.

\section{Hormone Therapy}

The efficacy, safety, and pharmacokinetic characteristics of hormone therapy are generally comparable between Asian and Caucasian patients with early or advanced BC [29-42]. For example, a subgroup analysis of the FALCON study showed that the treatment effects of fulvestrant versus anastrozole were generally consistent between the Asian and non-Asian populations (Table 1) [38]. However, differences in the clinical benefit and toxicity profile of some hormone therapies exist among non-Caucasians.

Pharmacogenetic differences may contribute to a reduced clinical benefit of tamoxifen therapy in Asians with BC [34, 35]. Tamoxifen is metabolized to its highly potent active metabolites endoxifen and 4-hydroxytamoxifen. Several cytochrome P450 (CYP) enzymes, including CYP2D6, perform an important step in the bioactivation process [43-45]. Furthermore, the CYP2D6 gene is highly polymorphic, leading to altered enzyme expression and function [45]. Accordingly, clinically relevant variations in CYP2D6 phenotype frequency between individuals and races could impact the efficacy of tamoxifen therapy $[33,34,46]$. The $C Y P 2 D 6^{*} 10$ variant, associated with reduced enzyme activity, is more common in Asians, and this results in significantly lower plasma concentrations of endoxifen and 4-hydroxytamoxifen, and poorer clinical outcomes for Asians with metastatic BC [34]. A meta-analysis investigating the effect of CYP2D6*10 polymorphisms on clinical outcomes in 1,794 Asian patients with $\mathrm{BC}$ across 15 retrospective studies concluded that the CYP2D6*10 variant reduces the efficacy of tamoxifen treatment, as illustrated by lower disease-free survival (DFS) and higher recurrence rates [35, 36].

Letrozole, an aromatase inhibitor, has been shown to be better tolerated by Black, Hispanic, Asian, Pacific Island, and native North American/Alaskan women, who reported a significantly lower incidence of hot flashes (49\% vs. 58\%; $p=0.02)$, fatigue ( $29 \%$ vs. $39 \% ; p=0.005)$, diarrhea ( $3 \%$ vs. $7 \%$; $p=0.033$ ), and arthritis ( $2 \%$ vs. $7 \% ; p=0.006)$ than Caucasians; these women did not achieve the same improvement in DFS [36]. This variability in letrozole efficacy and safety in Asians has been attributed to pharmacokinetic differences, poorer treatment adherence, and divergent menopausal experiences between races [36]. These results need confirmation in other trials of aromatase inhibitors, given the heterogeneity of the non-Caucasian cohort and the limited number of Asian patients.

\section{Anti-Human Epidermal Growth Factor Receptor 2 (HER2)-Targeted Therapies}

The recommended dosages of molecular targeted therapies are not based on body mass or surface area. In general, the pharmacokinetics, efficacy, and safety profiles of targeted therapies such as tyrosine kinase inhibitors (TKIs), monoclonal antibodies, and antibody-drug conjugates are comparable across races in patients with advanced BC (Table 1) [19, 47-54]. However, several studies have reported superior clinical outcomes with TKIs among Asians.

A numerically improved objective response rate (ORR; $66.4 \%$ vs. $51.3 \%$ ), clinical benefit rate (CBR; $70.2 \%$ vs. 60.2\%), and PFS [55.6 (95\% confidence interval (CI) 44.1-64.0) vs. 36.1 (95\% CI 32.1-40.0) weeks] have been observed in Asian patients with advanced disease who were administered neratinib-based therapy compared with nonAsians [53], which correlates with similar or greater invasive DFS in early BC $[52,53]$. Likewise, disease control with lapatinib in combination with capecitabine is considerably higher in Asian than Caucasian populations (58-59\% vs. 27-29\%) [51, 54], but these outcomes may not be entirely attributable to racial differences because Asian patients exhibited greater treatment adherence and a longer duration of treatment $[52,53]$. In addition, whether the improved efficacy was a result of the epidermal growth factor receptor inhibitor or the partner drug capecitabine could not be determined. A subgroup analysis of the DESTINY-Breast01 study 


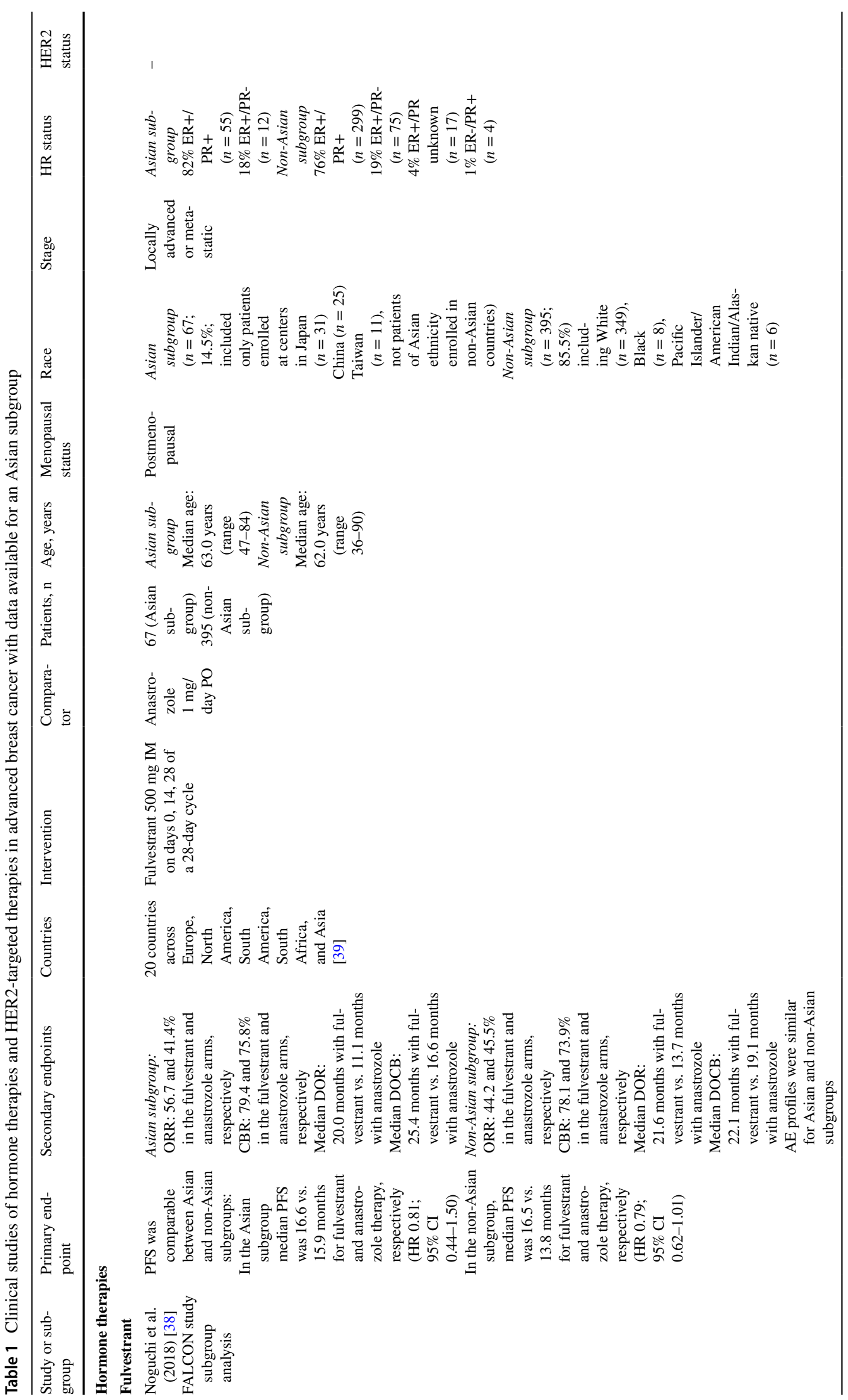




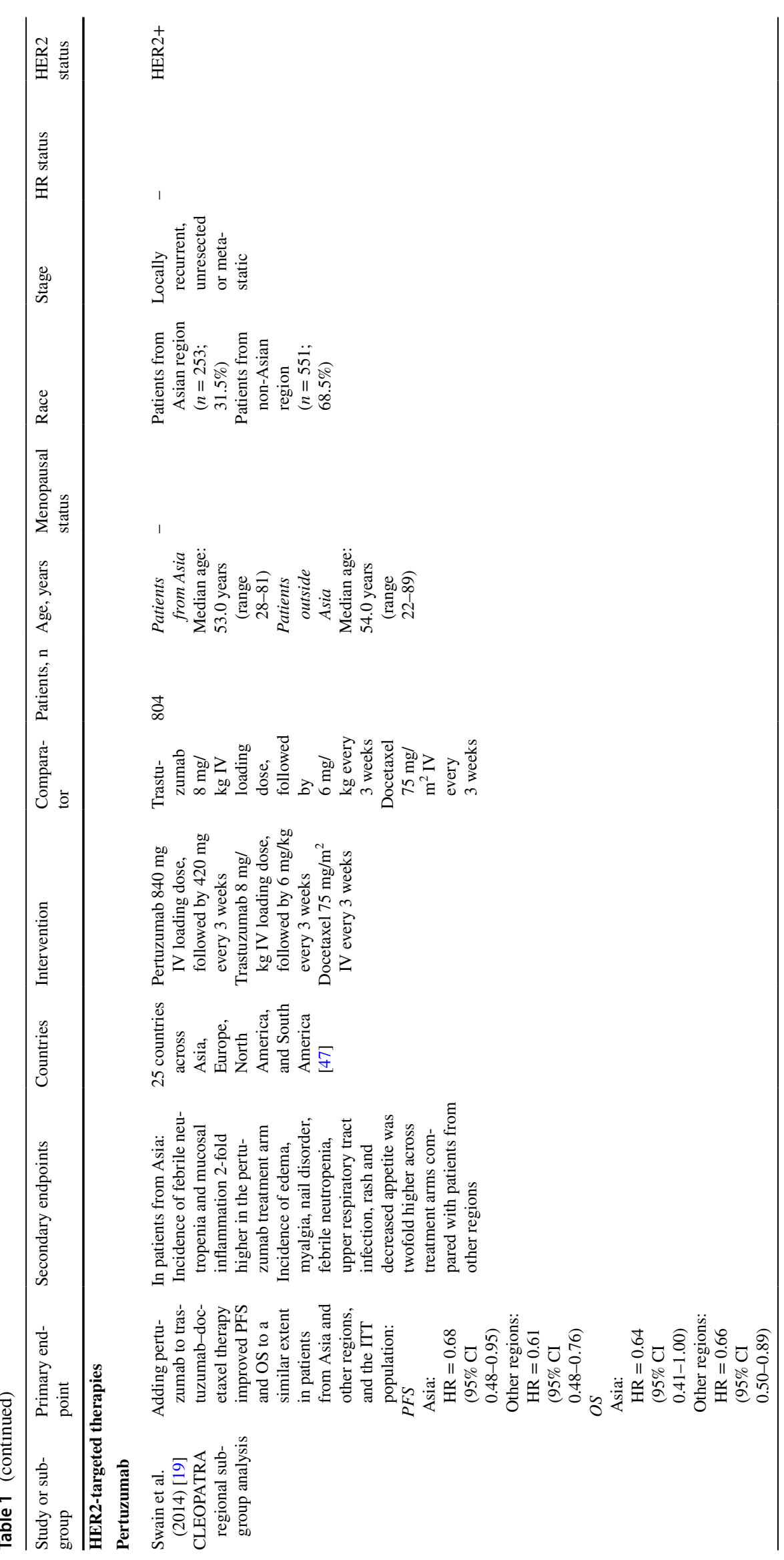




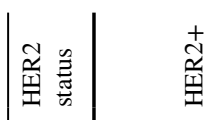
$\stackrel{+}{\stackrel{4}{\Psi}}$

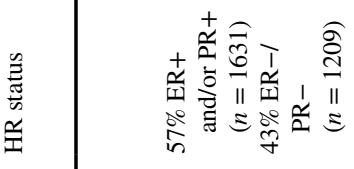

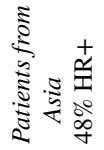

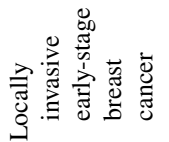

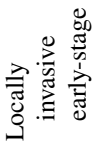

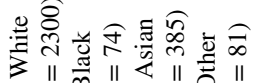

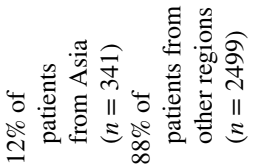

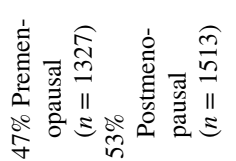

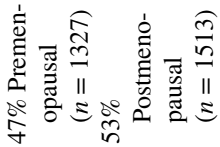

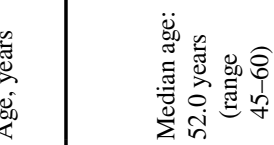

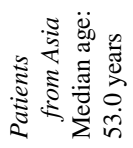
京
跡
$\frac{8}{\frac{8}{4}}$
$\frac{8}{\frac{8}{4}}$

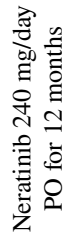

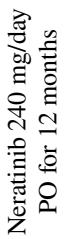

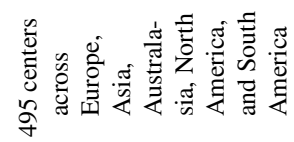
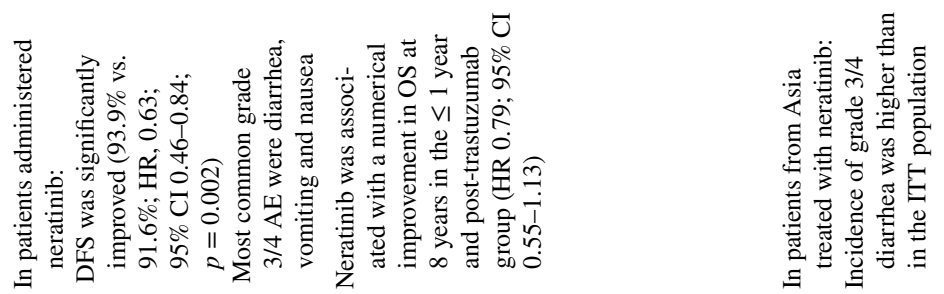
尊葶

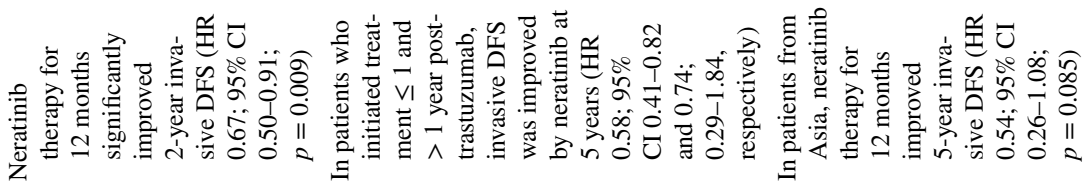




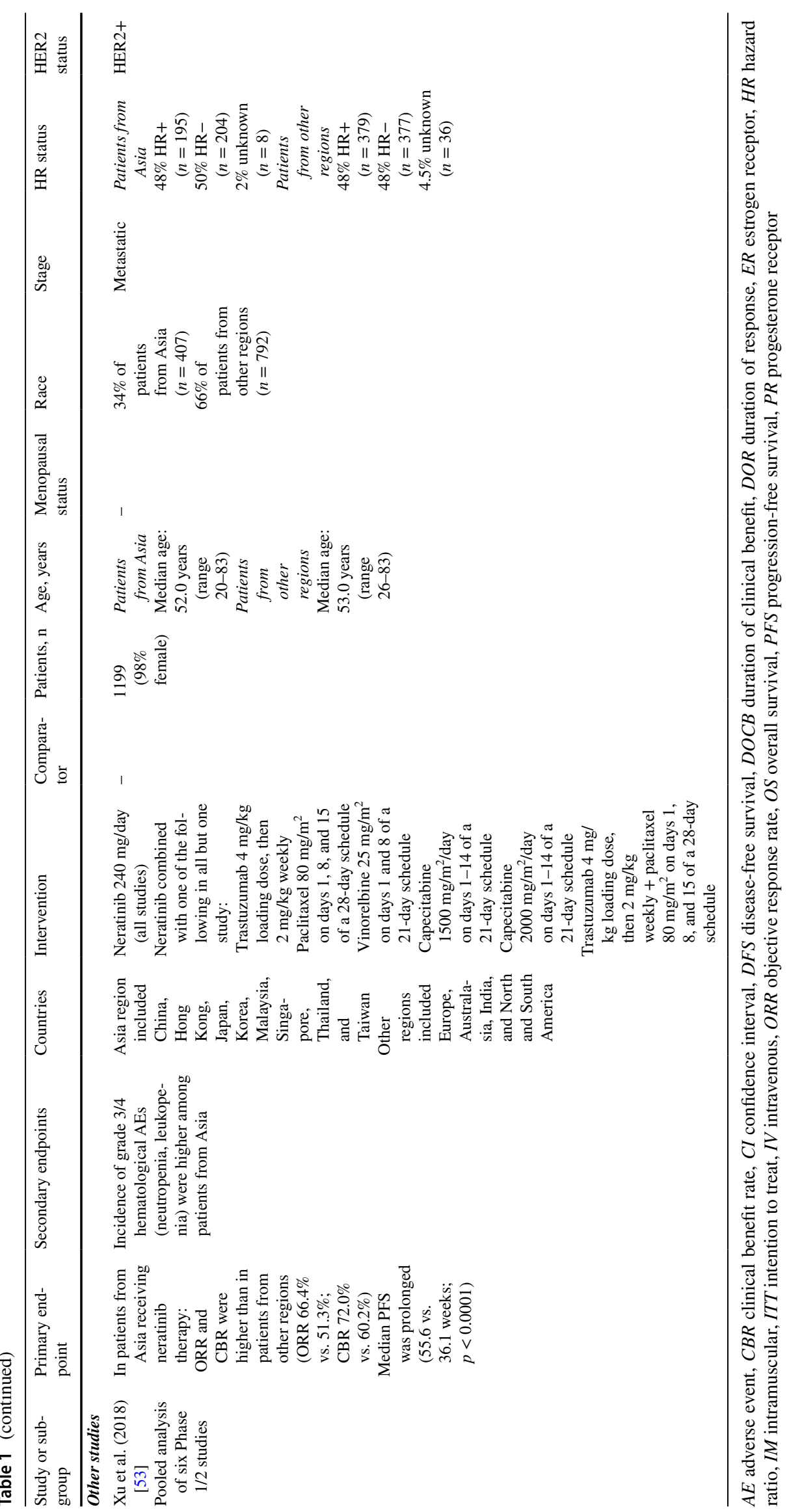


showed that race (Asian vs. non-Asian) did not impact the efficacy of trastuzumab deruxtecan in patients with HER2positive metastatic $\mathrm{BC}$ previously treated with trastuzumab emtansine [55].

Data regarding the safety profiles of targeted therapies are conflicting. For example, Asians treated with trastuzumab demonstrate fewer instances of cardiac toxicity compared with non-Asians [56], but patients treated with neratinib have higher rates of grade 3/4 diarrhea and hematological events [52, 53]. Similarly, trastuzumab emtansine (T-DM1) poses a greater risk of thrombocytopenia among Asians [57].

\section{Cyclin-Dependent Kinase (CDK) 4/6 Inhibitors}

The more recently conducted trials on CDK4/6 inhibitors have demonstrated increased effort to include Asians within the study subsets, especially for premenopausal patients. In the first-line setting for patients with advanced BC, consistent data have shown Asians deriving greater benefit from CDK4/6 inhibitors than their non-Asian counterparts or the overall intent-to-treat population (Table 2) [58-74]. For example, $\sim 70 \%$ of East Asian patients with measurable disease [PFS hazard ratio (HR) 0.33 (95\% CI 0.20-0.56)] responded to abemaciclib-anastrozole therapy versus 59\% of the overall population [PFS HR 0.54 (95\% CI 0.42-0.70)] in the MONARCH-3 study, although interactions between race/geographical location and outcomes for Asians were not formally tested $[60,73]$. The PFS HR in Asians treated with palbociclib in combination with letrozole was $0.48(95 \%$ CI $0.27-0.87)$ while that of non-Asians was 0.58 (95\% CI $0.45-0.74$ ) in the PALOMA-2 study (Table 2) [59]. The MONALEESA-2 study of ribociclib and letrozole combination therapy also demonstrated clinically meaningful PFS in Asians [HR 0.30 (95\% CI 0.13-0.66)] compared with the non-Asians [HR 0.60 (95\% CI 0.46-0.79)] [74]. Asians treated with ribociclib in the MONALEESA-7 study had greater benefits when compared with the non-Asians; the PFS HR in Asians was 0.41 (95\% CI 0.26-0.66) versus 0.66 (95\% CI 0.48-0.92) in non-Asians. Higher ORR and CBR was also achieved with ribociclib in Asians compared with non-Asians (ORR 59\% vs. 47\%; CBR $86 \%$ vs. 80\%) [61]. Furthermore, the HR for OS in Asians was 0.40 (95\% CI $0.22-0.72$ ) versus 0.91 (95\% CI 0.64-1.30) in non-Asians [75]. A recent meta-analysis confirmed that ethnicity influences efficacy of CDK4/6 inhibitor therapies (abemaciclib, palbociclib, ribociclib) as first-line treatment options in patients with advanced BC [76]. Specifically, among Asians $(n=492)$, the HR for PFS was 0.39 (95\% CI 0.29-0.51; $p<0.0001$ ) for combination CDK4/6 inhibitor-endocrine therapy compared with endocrine monotherapy, while in non-Asians $(n=2007)$ the HR for PFS for combination
CDK4/6 inhibitor-endocrine therapy versus endocrine monotherapy was 0.62 (95\% CI $0.54-0.71 ; p<0.0001)$, demonstrating a significant interaction between ethnicity and treatment effect on PFS $(p=0.002)$ [76].

In the second-line and beyond setting in advanced $\mathrm{BC}$, the benefits of adding a CDK4/6 inhibitor to fulvestrant in Asian patients were less apparent compared with benefits seen in Caucasian patients. While the MONARCH-2 study demonstrated the addition of abemaciclib led to comparable outcomes between East Asians versus the overall population in terms of PFS HR [0.52 (95\% CI 0.36-0.74) vs. 0.55 (95\% CI 0.45-0.68)] [70, 71] and OS HR [0.80 (95\% CI $0.52-1.24)$ vs. 0.76 (95\% CI 0.61-0.95)] [77], results from the PALOMA-3 and MONALEESA-3 studies did not show similar findings [78]. These results may be limited by the small number of Asians being included in the trials and subtle differences in eligibility criteria used in each study. The median PFS and OS HRs for the Asian population in the MONALEESA-3 study were 1.35 (95\% CI 0.57-3.19) and 1.42 (95\% CI $0.46-4.33)$, respectively [68, 79]. In the PALOMA-3 study, OS HR was 1.04 (95\% CI 0.57-1.93) in Asian patients versus 0.78 (95\% CI 0.60-1.01) in Caucasian patients, despite a similar PFS HR between Asian and non-Asian patients [Asian 0.49 (95\% CI 0.27-0.87); nonAsian 0.45 (95\% CI 0.34-0.59)] [63, 78]. In the monarchE study, Asian patients with high-risk early BC had clinically meaningful improvements in invasive disease-free survival (IDFS) and distant relapse-free survival (DRFS) with abemaciclib plus endocrine therapy versus endocrine therapy alone [80]. There was a $22.3 \%$ reduction in the risk of developing invasive disease with abemaciclib plus endocrine therapy versus endocrine therapy alone, while 2-year IDFS rates were $93.2 \%$ versus $90.1 \%$, and 2-year DRFS rates were 94.4\% versus $91.7 \%$. The benefits seen in Asian patients in monarchE were consistent with those seen in the overall population [80].

Although CDK4/6 inhibitors are generally well tolerated and exhibited an acceptable safety profile that is comparable between Asians and non-Asians [61,74], ethnic variation in AE profiles has been observed. For palbociclib, compared with non-Asians, a reduced rate of fatigue (19\% vs. $44 \%$ ), but increased incidence of neutropenia ( $92 \%$ vs. $78 \%$ ), stomatitis ( $41 \%$ vs. $24 \%$ ), rash (32\% vs. $11 \%$ ), and nasopharyngitis (21\% vs. $10 \%$ ) have been reported for Asians [63]. In the PALOMA-3 study, Asian ethnicity was significantly associated with an increased chance of developing grade $3 / 4$ neutropenia with palbociclib [81]. A similar finding was observed in the PALOMA-2 study, and the investigation of pharmacokinetics showed that geometric mean palbociclib $C_{\text {trough }}$ values were higher in Asians relative to non-Asians (93.8 vs. $61.7 \mathrm{ng} / \mathrm{mL}$ ), which indicated greater palbociclib exposure in Asians [82]. Pharmacogenetic analyses of the PALOMA-2 and PALOMA-3 studies have suggested an 
association of drug-related polymorphisms with palbociclibrelated neutropenia [83, 84]. Compared with the global study population, a higher rate of neutropenia was also seen among East Asian patients treated with abemaciclib for metastatic or recurrent $\mathrm{BC}$, along with a greater incidence of leukopenia, alopecia, and increased alanine aminotransferase and aspartate aminotransferase levels [73]. In PALOMA-2 dose reductions were used to manage tolerability issues, and Asian patients had dose reductions more frequently than non-Asian patients [82], which has the potential to affect efficacy; however, an exposure-response analysis showed that palbociclib exposure had no impact on PFS [85].

For ribociclib, a higher rate of grade 3/4 QT-interval prolongation occurs among Asians than non-Asians (3.8\% vs. $0.6 \%$ ) [61]. The low number of Asians enrolled across studies greatly limits the ability to make formal inter-ethnic comparisons. A meta-analysis assessing the influence of ethnicity on toxicity associated with combination CDK4/6 inhibitor and endocrine therapy reported that the addition of a CDK4/6 inhibitor resulted in a higher incidence of neutropenia in Asians when compared with non-Asians (91\% vs. $75 \%$; $p$-value between groups $0.00001 ; p$-value for ethnicity interaction 0.07) [76]. Likewise, Asians tended to experience lower rates of diarrhea compared with non-Asians, although the interaction was not statistically significant ( $15 \%$ vs. $32 \%$; $p$-value between groups 0.003 ; $p$-value for ethnicity interaction 0.35) [76]. While Asian ethnicity was generally associated with a significantly lower risk of nausea ( $p$-value for ethnicity interaction 0.007$)$, the difference was not significant (39.4\% vs. $42.4 \%$; $p$-value between groups 0.76) [76]. Interstitial lung disease (ILD) is another class of AE noted in the Asian population, especially in Japan [86]. Differences in genetic sensitivity and variation in reporting ILD as an adverse drug reaction may play a prominent role in the higher incidence rates, although further studies are warranted for validation [86, 87].

Overall, neutropenia appears to be the most common treatment-related $\mathrm{AE}$ in Asians treated with a CDK4/6 inhibitor. This is usually manageable through dose reduction or delay and does not affect treatment efficacy, or increase the incidence of neutropenic fever $[61,63,73,76,88,89]$. The generally lower body mass in Asians under a recommended flat dose of CDK 4/6 inhibitors has been proposed as a possible factor that leads to higher toxicities [25]. Genetic factors also play a role, with a Phase $1 \mathrm{~b}$ study finding that the maximum tolerated dose of ribociclib was $300 \mathrm{mg}$ in Japanese patients versus $600 \mathrm{mg}$ in non-Japanese Asians [90]. Drug exposure seems relatively similar among Asian and non-Asian patients according to the pharmacokinetic profiles $[63,91]$.

\section{Mammalian Target of Rapamycin (mTOR) Inhibitors}

Few studies have explored racial differences in the efficacy and safety of mTOR inhibitors in patients with BC, but currently available data suggest similar efficacy and safety profiles for Asian and non-Asian patients with advanced BC (Table 3) [92-95]. Specifically, the addition of everolimus to exemestane treatment produces similar benefits in survival among Asian (Chinese and Japanese) and non-Asian patients, with a median PFS of 8.5 months versus 7.3 months [93]. The addition of everolimus is associated with more toxicity compared with hormone therapy alone, resulting in a higher proportion of dose reductions and treatment discontinuations [96]. Although everolimus treatment is considered to be well tolerated and safe to use in Asians, some AEs are more common among Asians when compared with nonAsians, such as dysgeusia ( $31 \%$ vs. $20 \%$ ), pneumonitis (23\% vs. $15 \%$ ), nail disorder ( $22 \%$ vs. $5 \%$ ), increased lactate dehydrogenase ( $14 \%$ vs. $4 \%$ ), ILD (13\% vs. < $2 \%$ ), and stomatitis ( $80 \%$ vs. 54\%) [93]. These AEs can generally be managed through early intervention and dose modification [93].

\section{Bone-Targeted Therapies}

Due to an increased risk of bone metastases and treatmentrelated bone loss, patients with $\mathrm{BC}$ are often treated with denosumab or bisphosphonates to prevent and treat skeletal-related events [97-99]. Several studies have demonstrated comparable efficacy, safety, and pharmacokinetics for denosumab and zoledronic acid in Asian (predominantly Japanese) cohorts (Table 4) [97, 98, 100] and non-Asian cohorts [101-104]. For example, Japanese women with BC-related bone metastases show similar baseline levels of the bone turnover marker urinary $\mathrm{N}$-telopeptide corrected for creatinine (uNTx/Cr) to non-Japanese (White and Hispanic) patients following denosumab treatment, along with comparable sustained suppression of uNTx/Cr [97]. Similarly, zoledronic acid is effective for preventing aromatase inhibitor-associated bone loss in postmenopausal Japanese women [98], and has been shown to significantly reduce skeletal complications by $39 \%$ in Japanese women with BC and bone metastases [100]. While higher rates of low-grade pyrexia, fatigue, abdominal pain, and hypocalcemia have been reported in Japanese women with zoledronic acid compared with placebo, zoledronic acid is generally well tolerated [100]. 


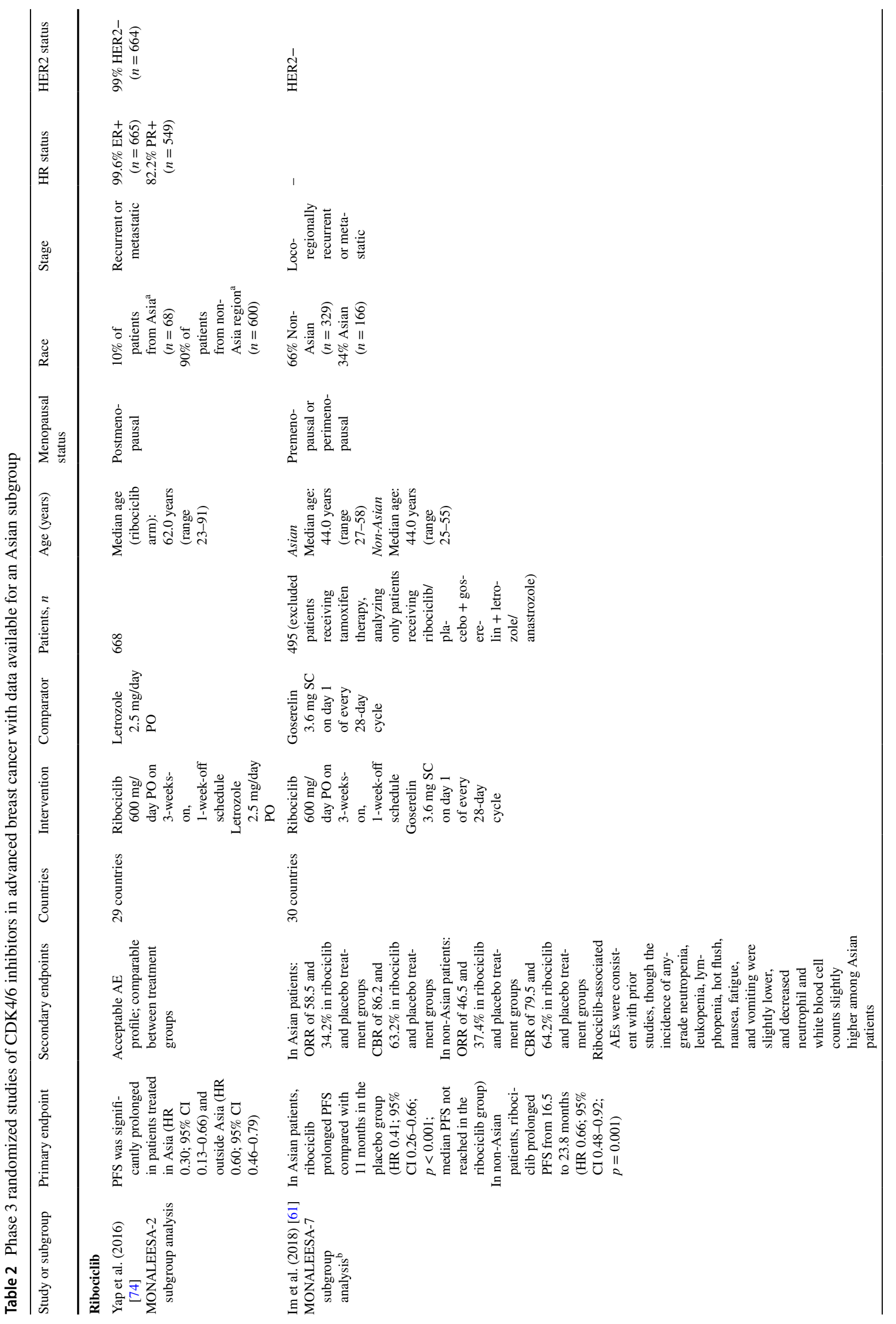




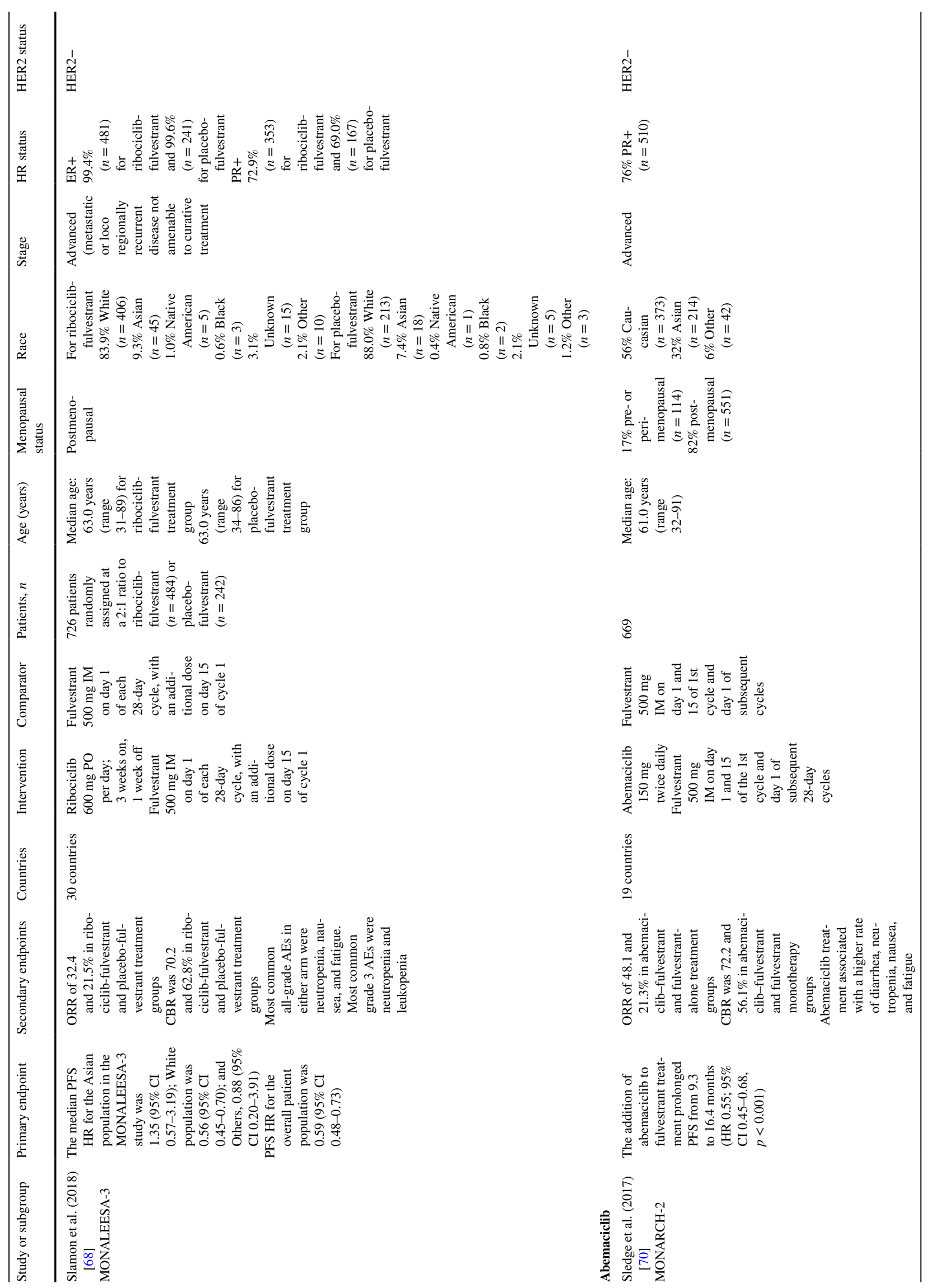




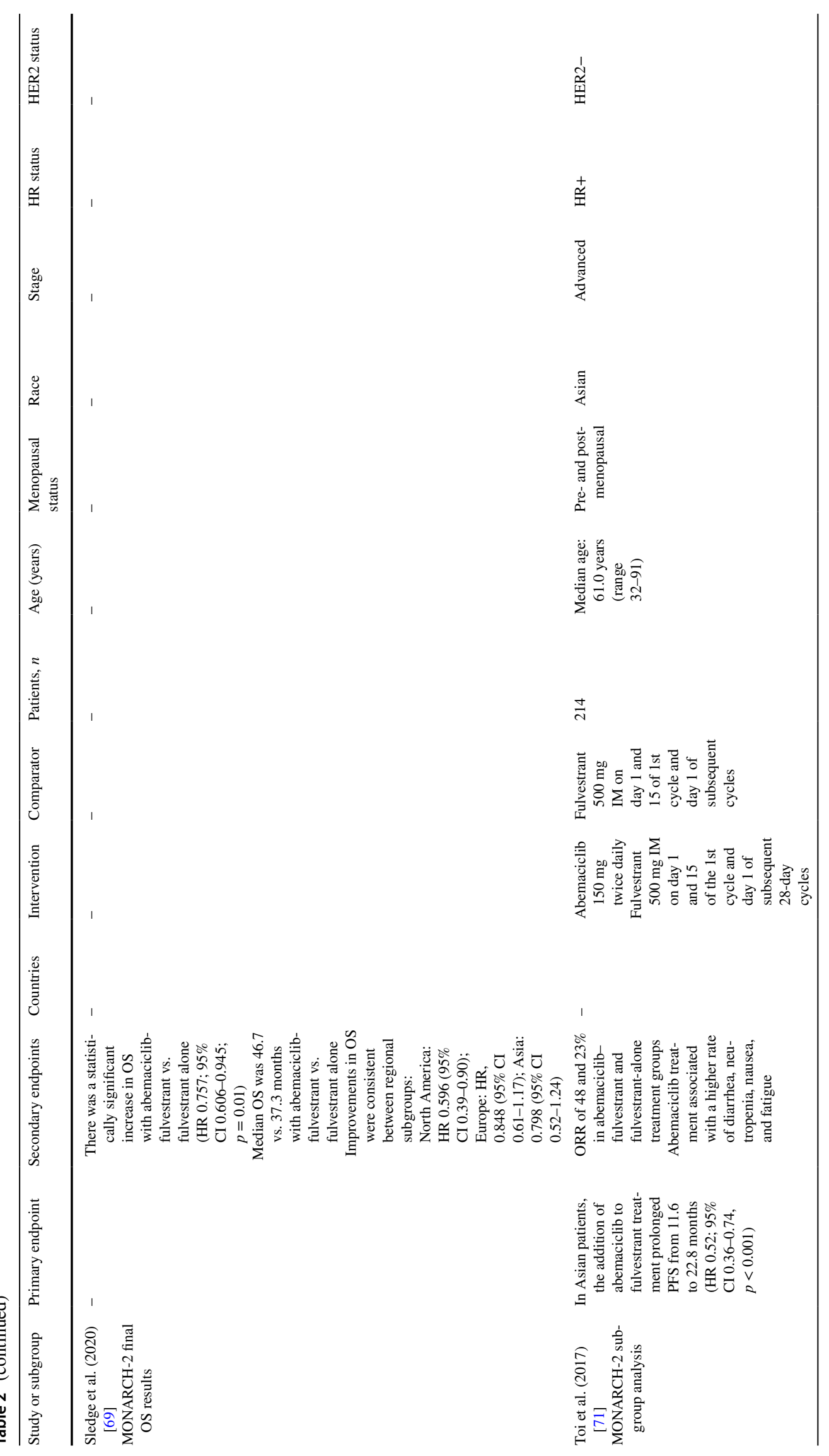




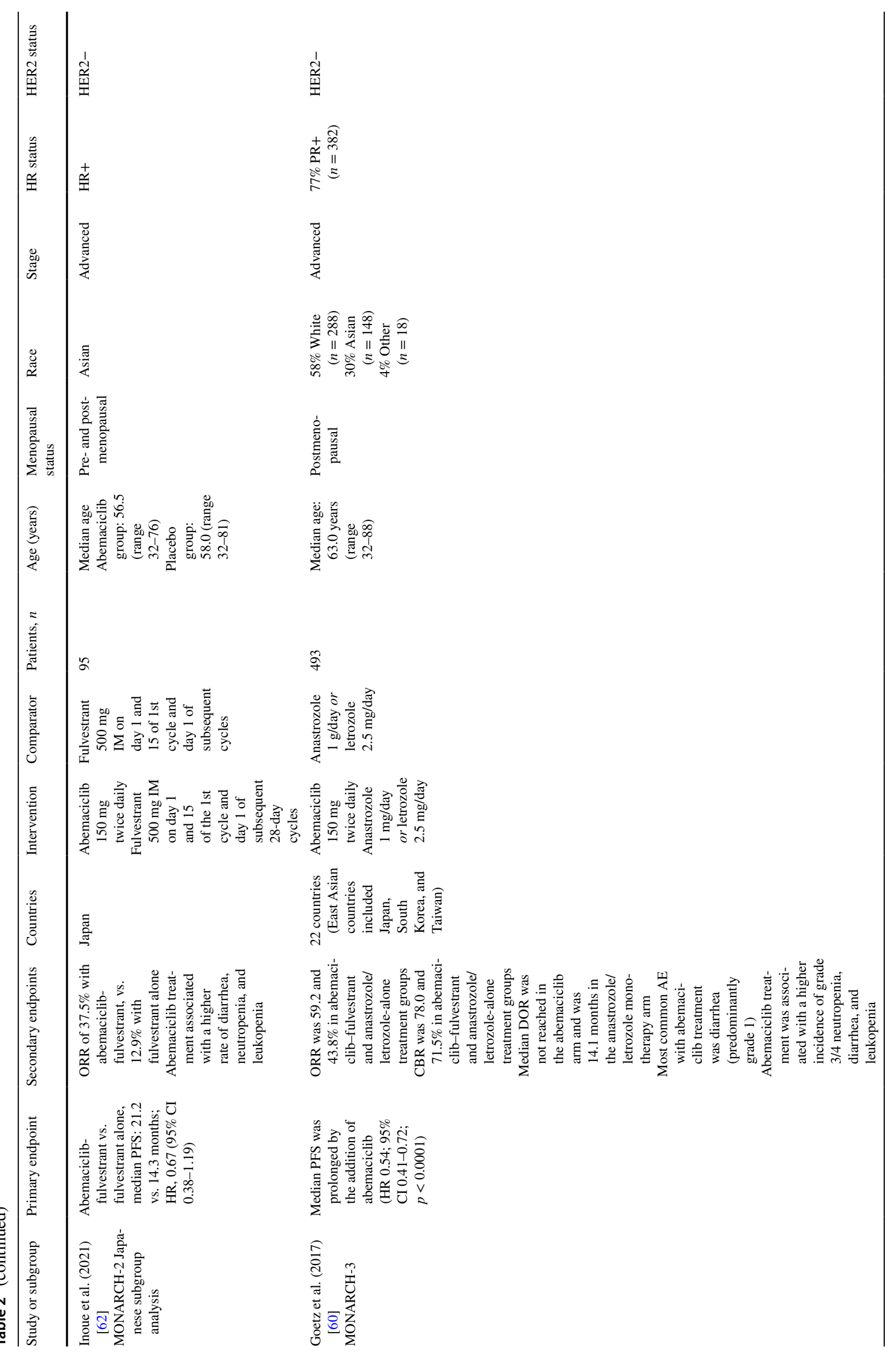




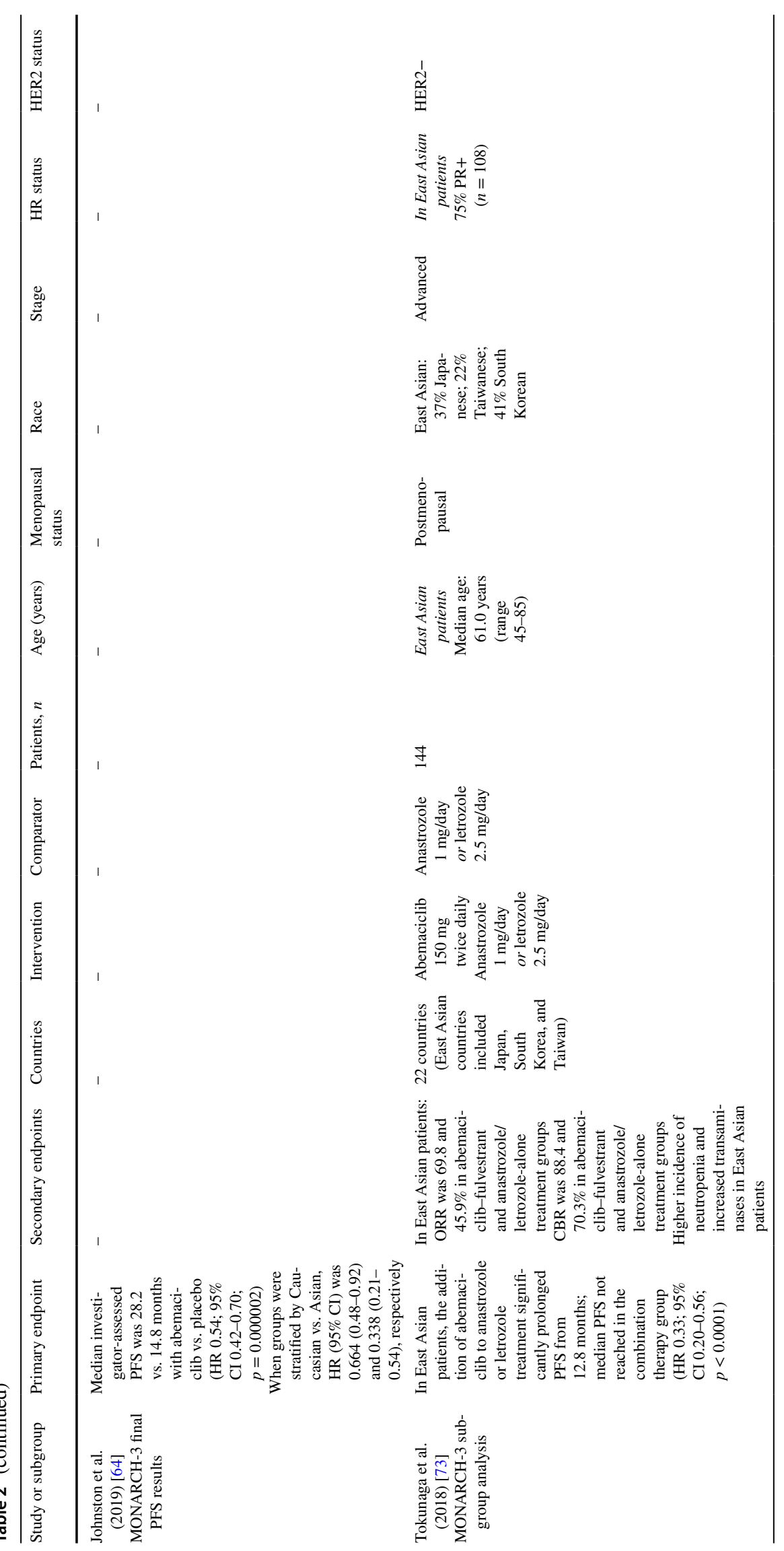




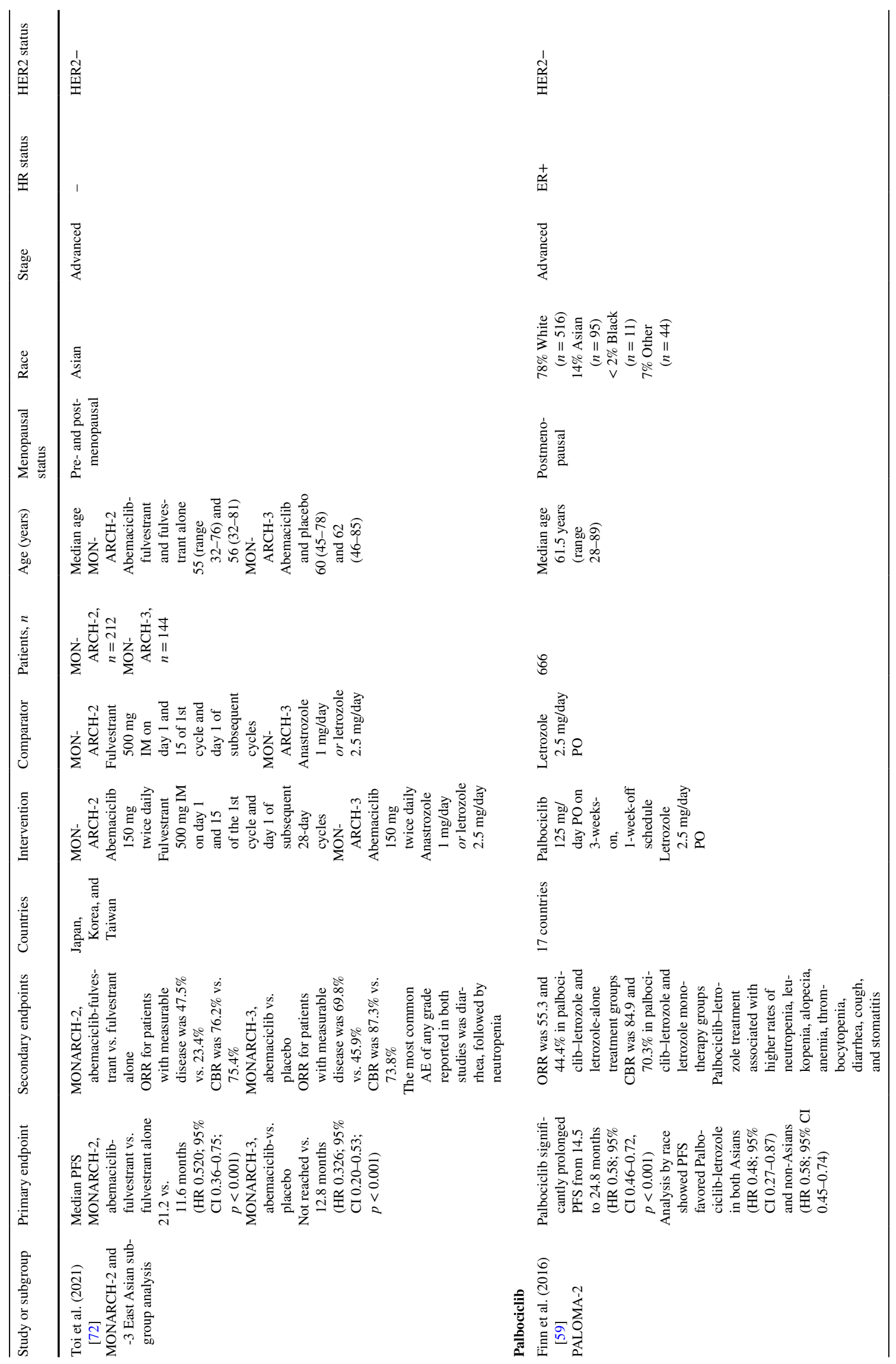




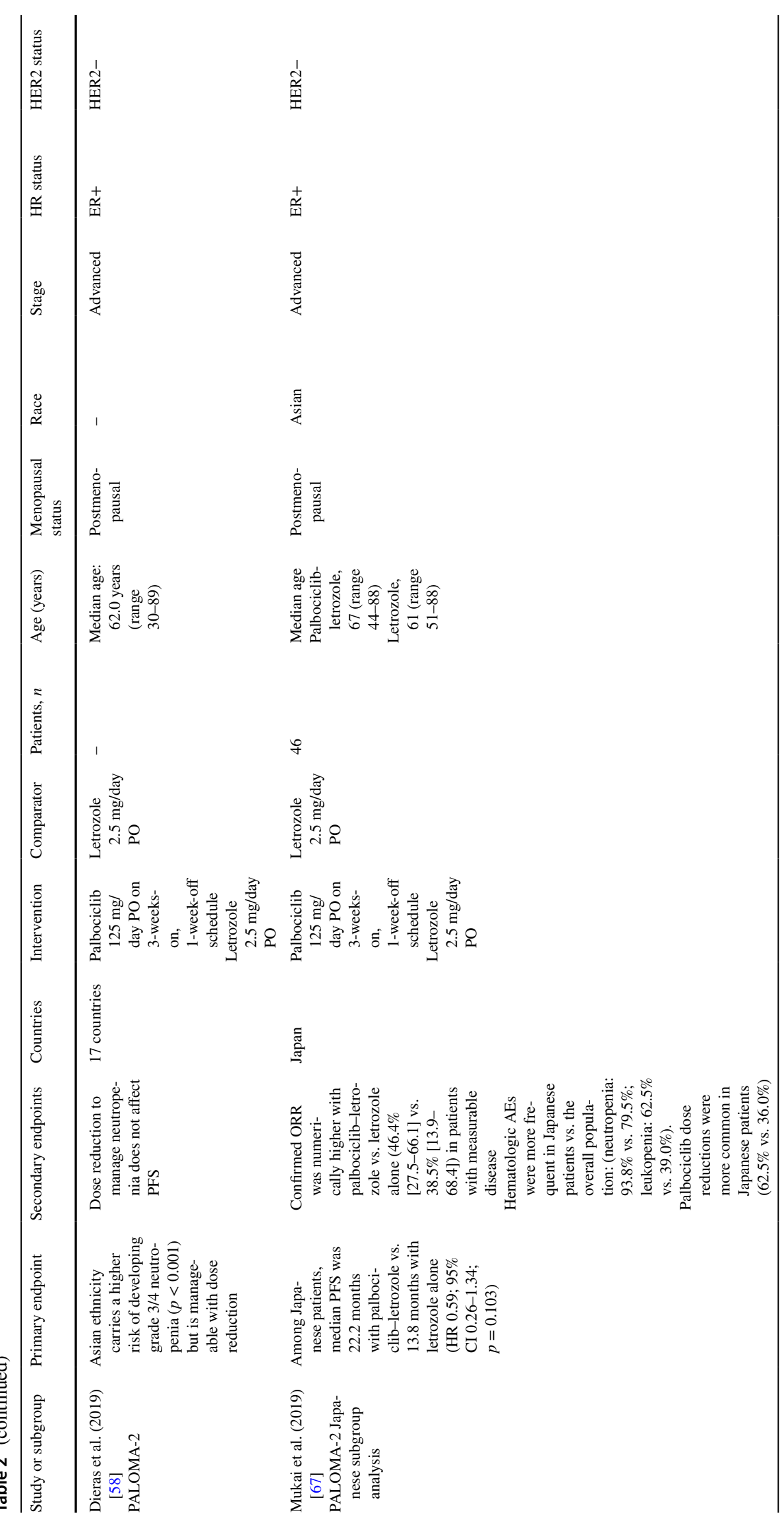




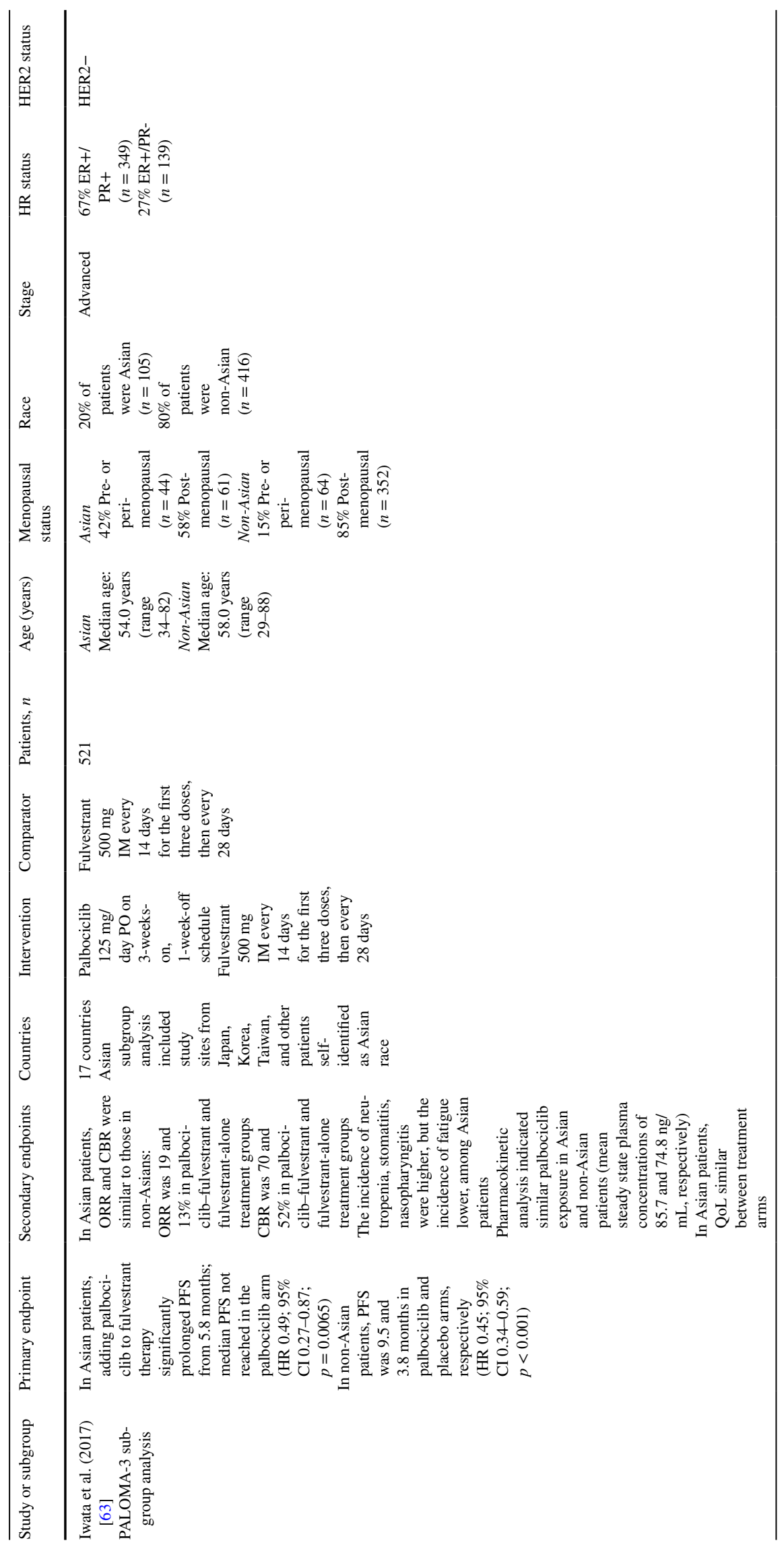




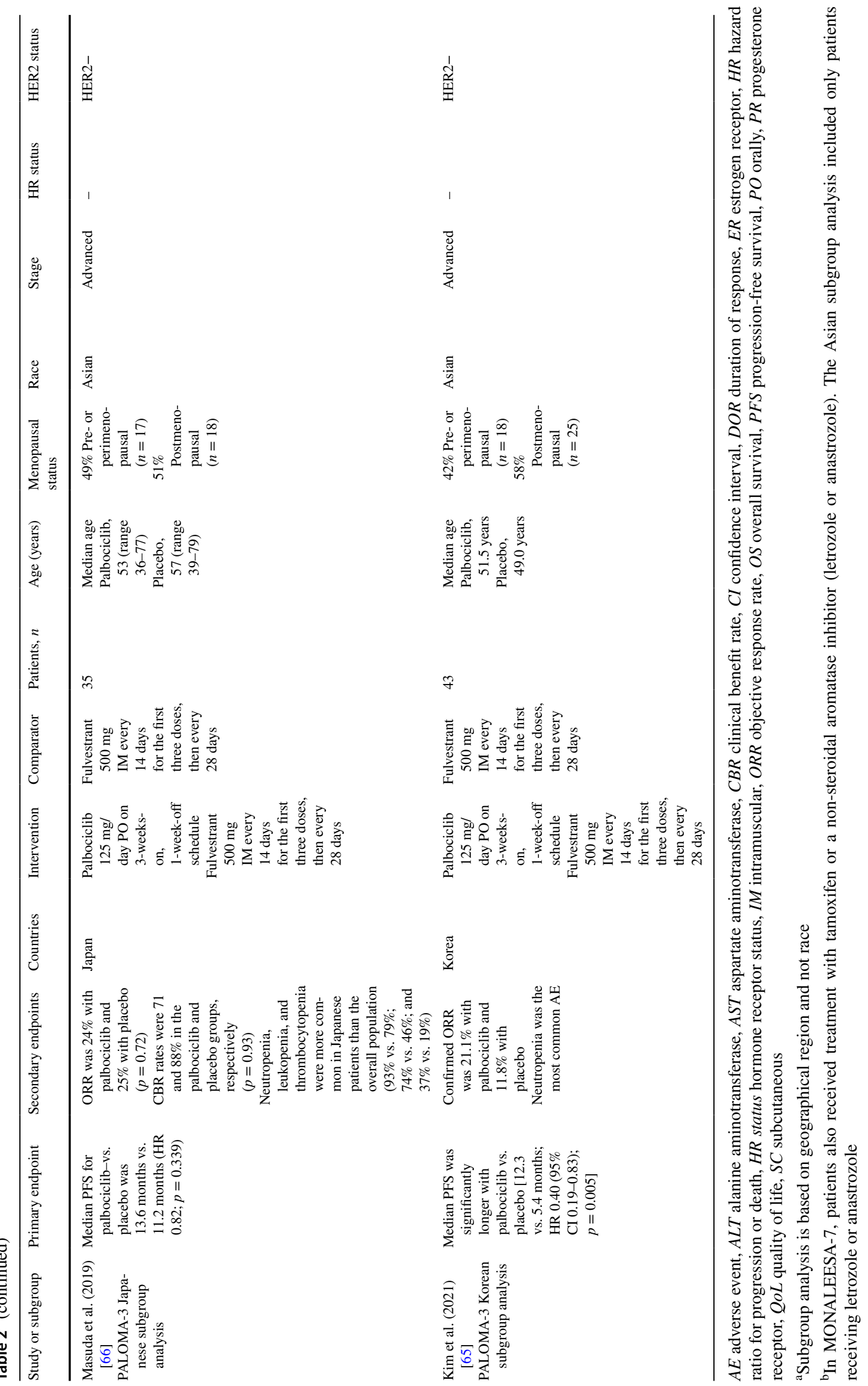




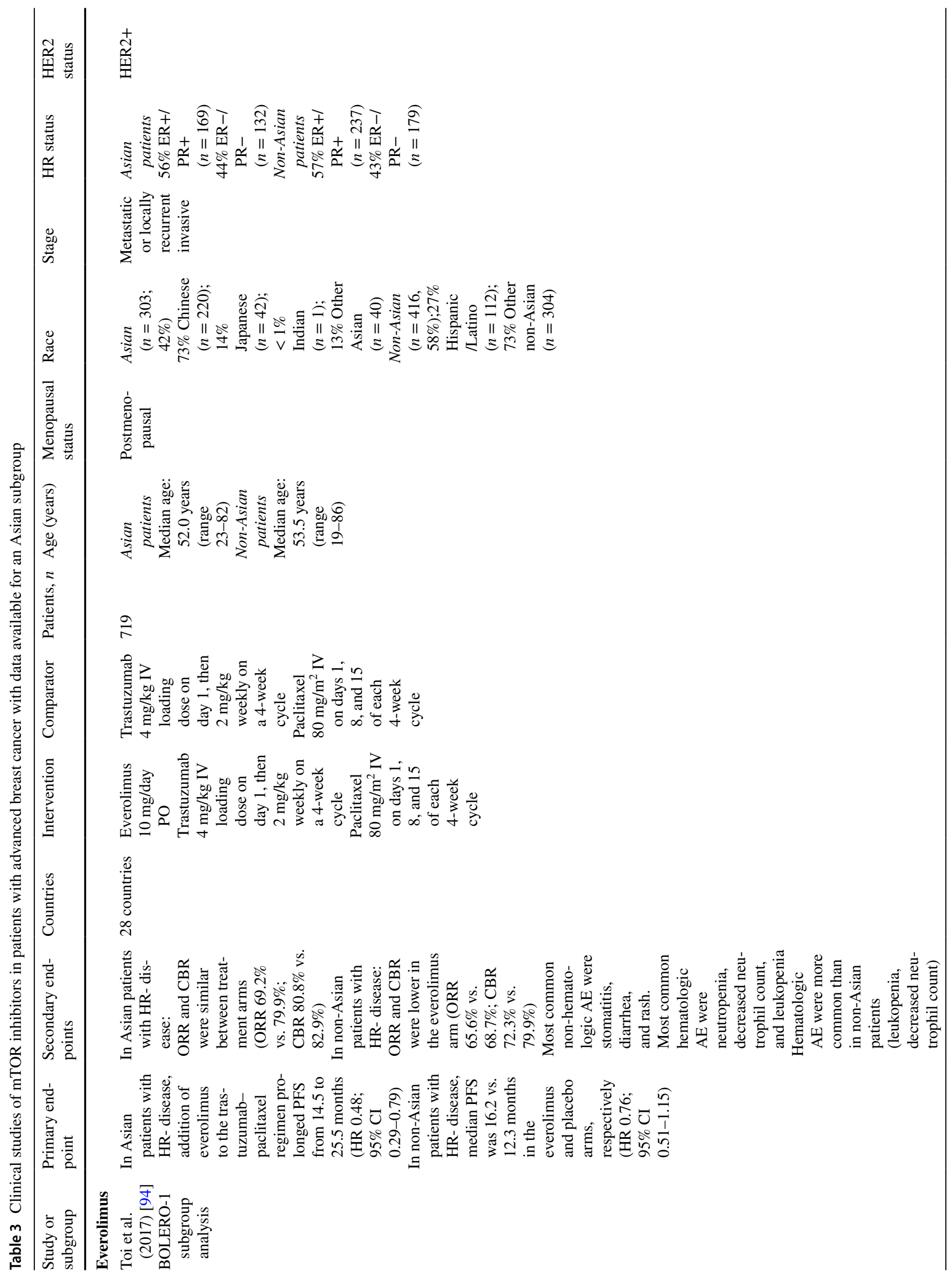




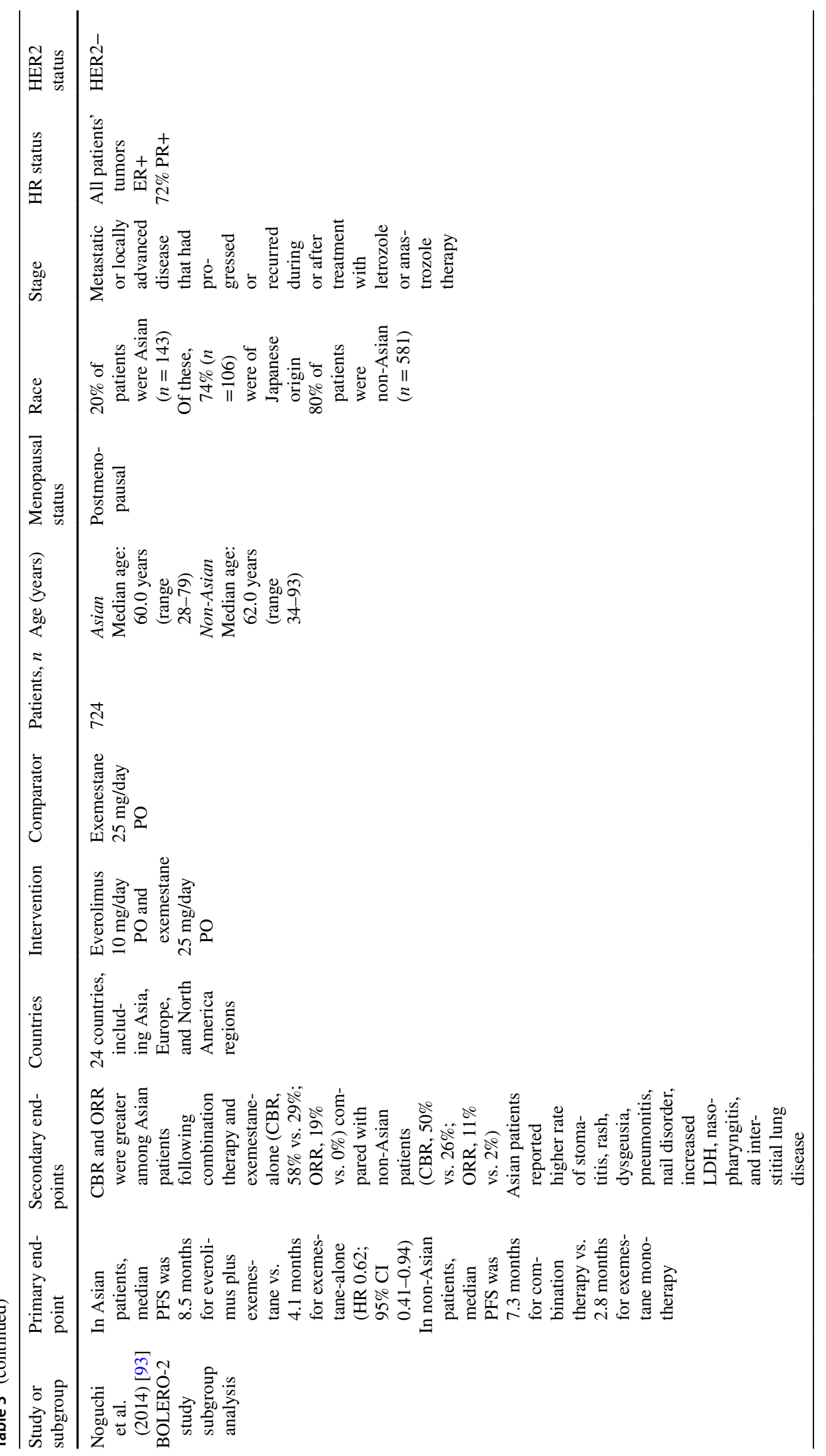




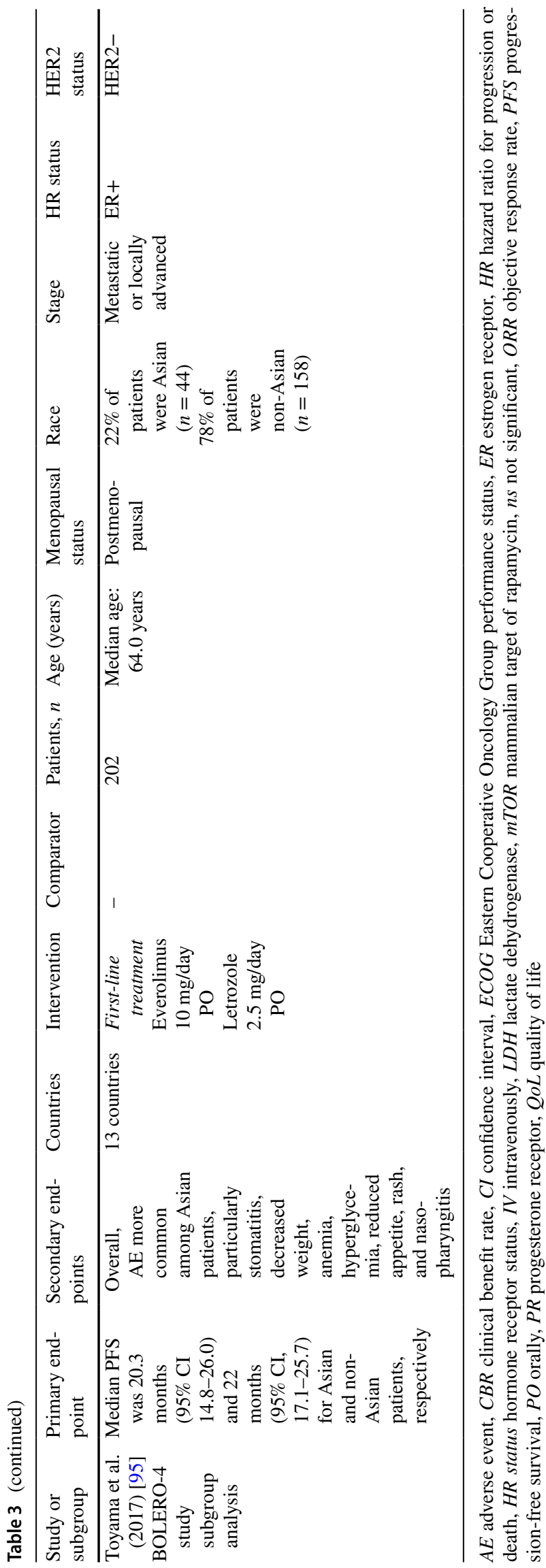

\section{Poly-ADP Ribose Polymerase (PARP), Phosphoinositide 3-Kinase (PI3K), and Checkpoint Inhibitors}

Of the PARP inhibitors under investigation for the treatment of locally advanced/metastatic BC, olaparib and talazoparib have data available for both overall populations and Asian subgroups (Table 5), which generally show that efficacy in Asian subgroups was similar to that in the overall population [105-110]. The OlympiAD study investigated olaparib versus physician's choice of chemotherapy, and while the study was not powered to detect differences between races, the Asian subgroup analysis found that similar to the overall population, there was a greater clinical benefit with olaparib than with chemotherapy with regard to PFS and response rates [106]. Olaparib was well tolerated in Asian patients, having a lower rate of grade $\geq 3$ AEs than chemotherapy [106]. The number of Asian patients in the EMBRACA studies of talazoparib versus chemotherapy was limited ( $n=33$; Table 5); however, both efficacy (as measured by PFS and response rates) and AEs were all consistent with the overall population [110].

The SOLAR-1 study showed that the PI3K inhibitor alpelisib plus fulvestrant prolonged PFS versus placebo plus fulvestrant in patients with PI3K-mutated, hormonereceptor positive, HER2-negative breast cancer who have previously received endocrine therapy (Table 5) [111-113]. An analysis of the SOLAR-1 results according to geographic region showed that in Asia, median PFS and response rates were improved with alpelisib plus fulvestrant versus placebo plus fulvestrant, consistent with the overall population; notably, the ORR in Asia was numerically higher than the ORRs seen in other regions (46.7\% vs. $21.1 \%$ and $21.4 \%$ in North America and Latin America, respectively) [113]. The most common AEs of any grade in the Asian subgroup were hyperglycemia and decreased appetite (75 and 58\%, respectively) [113]; these occurred in the alpelisib group of the main cohort at a frequency of 64 and 36\% [111].

The checkpoint inhibitor atezolizumab was investigated in patients with advanced triple-negative $\mathrm{BC}$ in the IMpassion130 study (Table 5) [114-116]. In IMpassion130, the White and Asian subgroups had similar median PFS [115], and a subgroup analysis of the 65 Japanese patients participating in IMpassion130 showed consistent results to those in the overall population [114]. Fewer Japanese patients withdrew from IMpassion130 because of AEs compared with the overall population, and generally no new safety signals were observed in this subgroup [114]. Another checkpoint inhibitor that is being investigated in patients with $\mathrm{BC}$ is pembrolizumab, in the KEYNOTE studies (Table 5). To date, much of the KEYNOTE data in Asian patients are available only in abstract form; all abstracts reported a benefit 


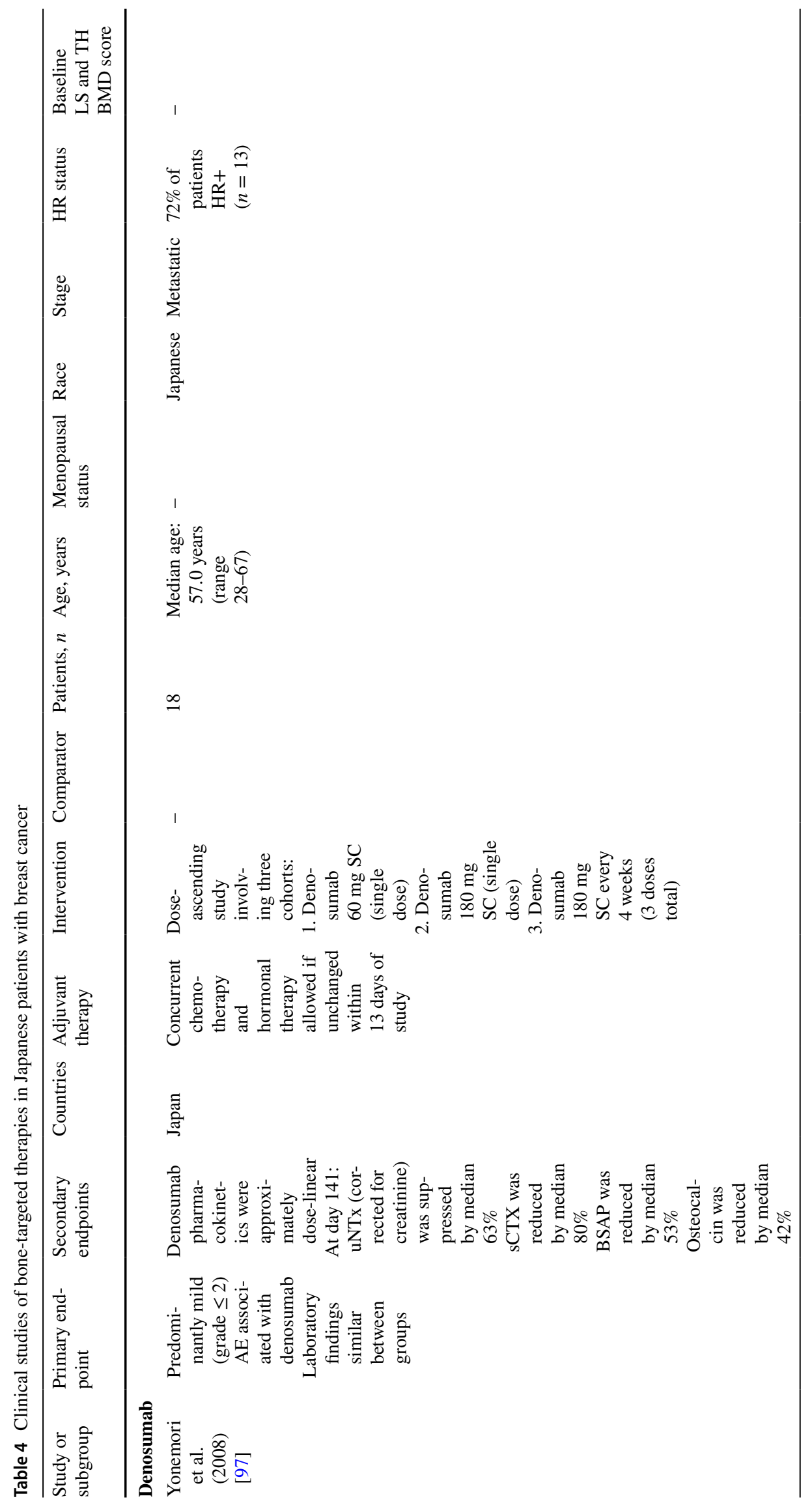




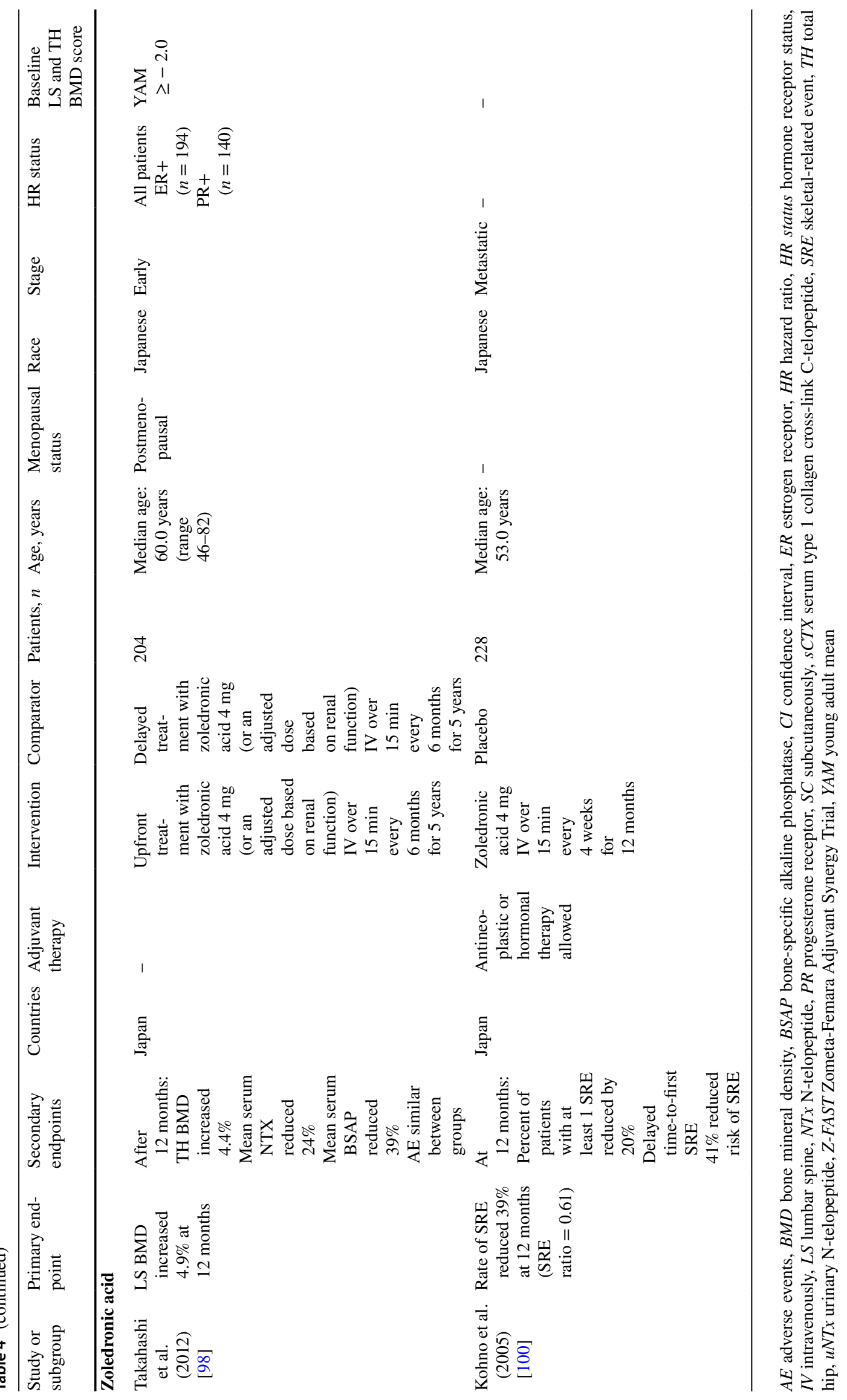


of pembrolizumab versus comparator (placebo or standard therapy) that was consistent with the overall population [117-119]. Pembrolizumab was well tolerated, with AEs consistent with the known safety profile $[117,118]$.

\section{Future Directions}

Asians are often under-represented in clinical trials of BC therapies, limiting conclusions regarding the efficacy and safety of different therapies for this population [3, 120]. While subgroup analyses comparing Asian versus non-Asian populations have been performed in some large international studies, regional and local studies are often required to confirm outcomes in Asian populations. For example, China's National Medical Products Administration requires large international trials that include at least 100 Chinese patients per intervention, in addition to local pharmacokinetic studies [3]. Similarly, Japan's Ministry of Health, Labor, and Welfare and Pharmaceuticals and Medical Devices Agency regulatory review requires pharmacokinetic, efficacy, safety, and medical data for Japanese subjects, which leads to initiation of additional clinical trials in Japan [121]. This approval system has been criticized for requiring data from only a small number of Japanese patients that may be inadequate to detect ethnic differences in efficacy and safety [121]. Hence, pharmacovigilance programs in Asian countries play a critical role in post-approval safety monitoring and reporting of AEs [122].

A clear, stage-specific, survival gap remains among different ethnicities despite significant improvement in overall $\mathrm{BC}$ outcomes, suggesting the need for inclusion of nonbiologic factors, including treatment differences, to explain observed outcome disparities [123]. A lack of understanding of racial and ethnic differences in patient response to pharmacological interventions also has downstream effects for patients by limiting their access to more effective or safer treatments. Likewise, the social, cultural, and economic settings represent challenges in applying the results and recommendations from studies enrolling largely non-Asian populations [1,3]. Future studies can help to overcome these challenges by actively engaging clinical trial centers in Asia to facilitate greater recruitment of Asians into clinical trials and more robust subgroup analyses of outcomes in Asians [3].

The field of genomics is also providing greater insight in tumor biology, enabling molecularly defined prognostic staging, which could have important implications for Asians with BC [3, 7, 124, 125]. Currently, prognostic staging based on multigene analysis draws from a predominantly Caucasian dataset, offering limited usefulness for risk stratification and therapy selection in Asians, for whom these tests have not yet been validated [3, 124]. Genomics provides an opportunity to establish the molecular profiles and biomarkers for subtypes of BCs that are more prevalent in Asian populations, which can guide treatment selection, and may be used to guide dosing strategies and inform cost-benefit analyses [122, 124]. Used together, tumor genomics and patient pharmacogenetics may facilitate more effective, safer, highly personalized treatments for Asians [125].

\section{Conclusions}

Asian and non-Asian patients with $\mathrm{BC}$ have different risk profiles and tumor biology, in addition to possible racerelated differences in pharmacogenetics and environmental factors [122, 124], which can influence the extent to which interventions and treatments validated in Western populations can be generalized and applied to Asian settings.

The efficacy of most BC chemotherapies and hormonal therapies appears to be broadly similar in Asian and non-Asian populations, with the exception of tamoxifen in patients with a $C Y P 2 D 6^{*} 10$ polymorphism, which is more common in Asians [29, 32, 35, 37, 38, 41, 42, 126-128]. Similarly, comparable efficacy is seen between Asian and non-Asian patients treated with anti-HER2-targeted therapies.

In contrast, the first-line studies with CDK4/6 inhibitors suggest potential race-related differences in the efficacy of these agents [76]. In particular, Asians appear to derive greater benefit from CDK4/6 inhibitor therapy than non-Asians $[73,76]$, which may be driven by variations in pharmacodynamics given the limited differences in pharmacokinetics [63, 129].

Furthermore, small Asian populations in clinical trials may limit insight into ethnic differences in efficacy and safety profiles of treatments for BC. Notably, differences in efficacy between Asian and overall populations have generally only been found in subgroup analyses with higher numbers of Asians, which has limited statistical validity and would be expected to increase the likelihood of any differences being observed $[61,63,73]$. In addition, the use of varying definitions of Asian race or ethnicity and combination therapies in studies of CDK4/6 inhibitors make it difficult to develop a clear understanding of the relative clinical profile of CDK4/6 inhibitors in Asian versus non-Asian patients [76]. Therefore, further studies are necessary to elucidate any race-related variation in response to CDK4/6 inhibitors and underlying mechanisms.

Asians experience a higher rate of hematological toxicity, particularly neutropenia, following administration of chemotherapy, targeted therapies, and possibly CDK4/6 inhibitors. The underlying mechanisms resulting in these outcomes are not well understood, but these AEs can generally be 


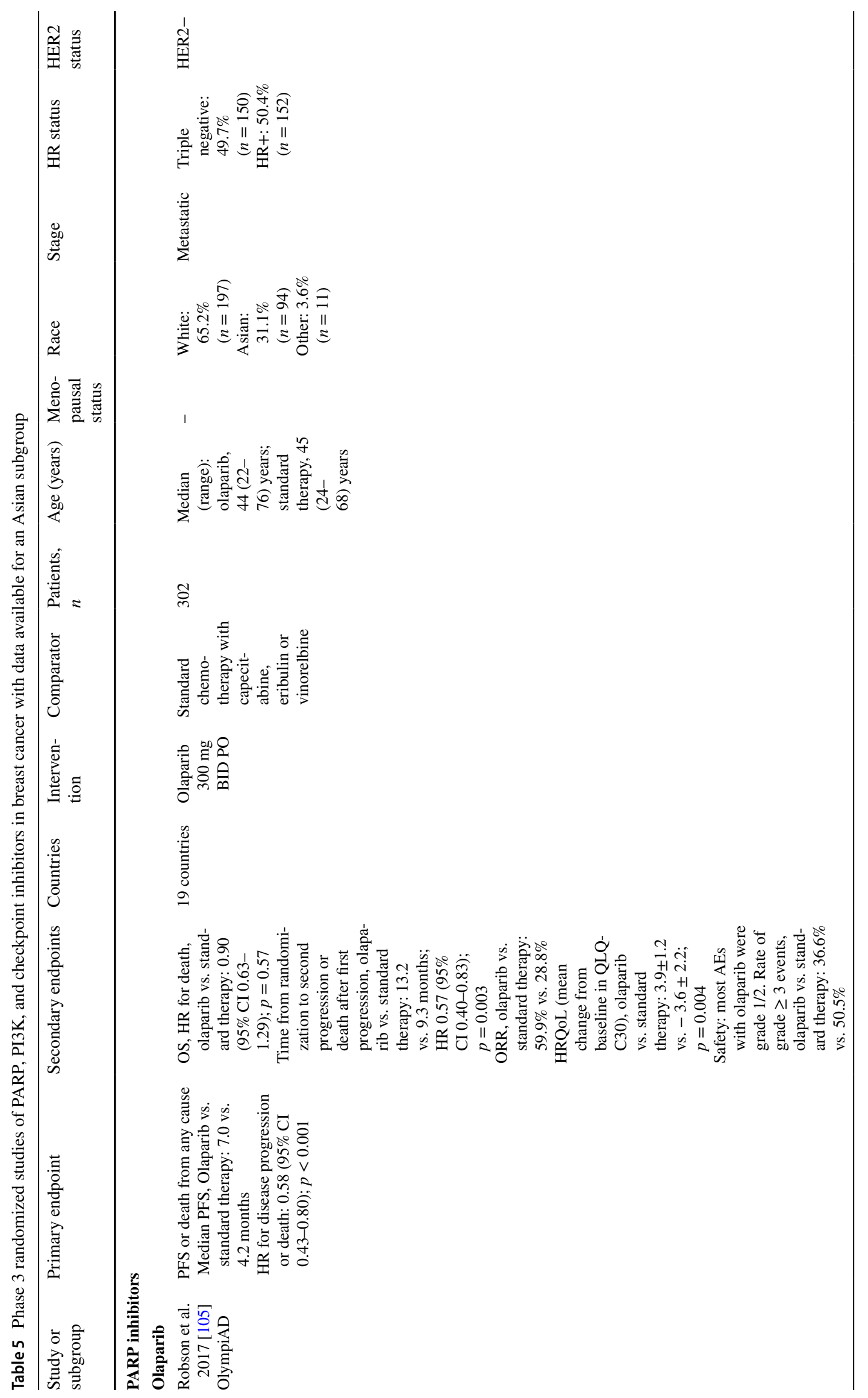




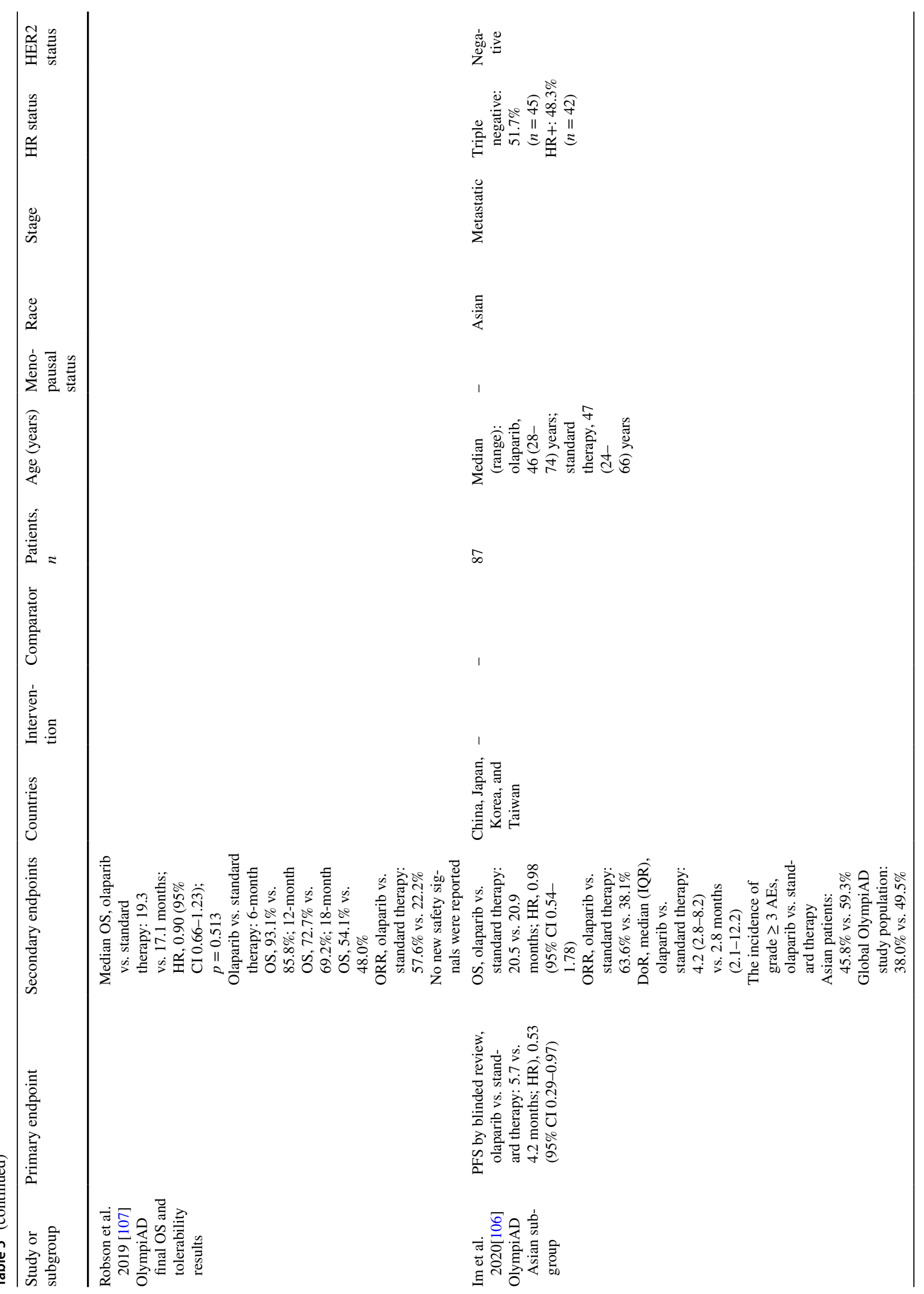




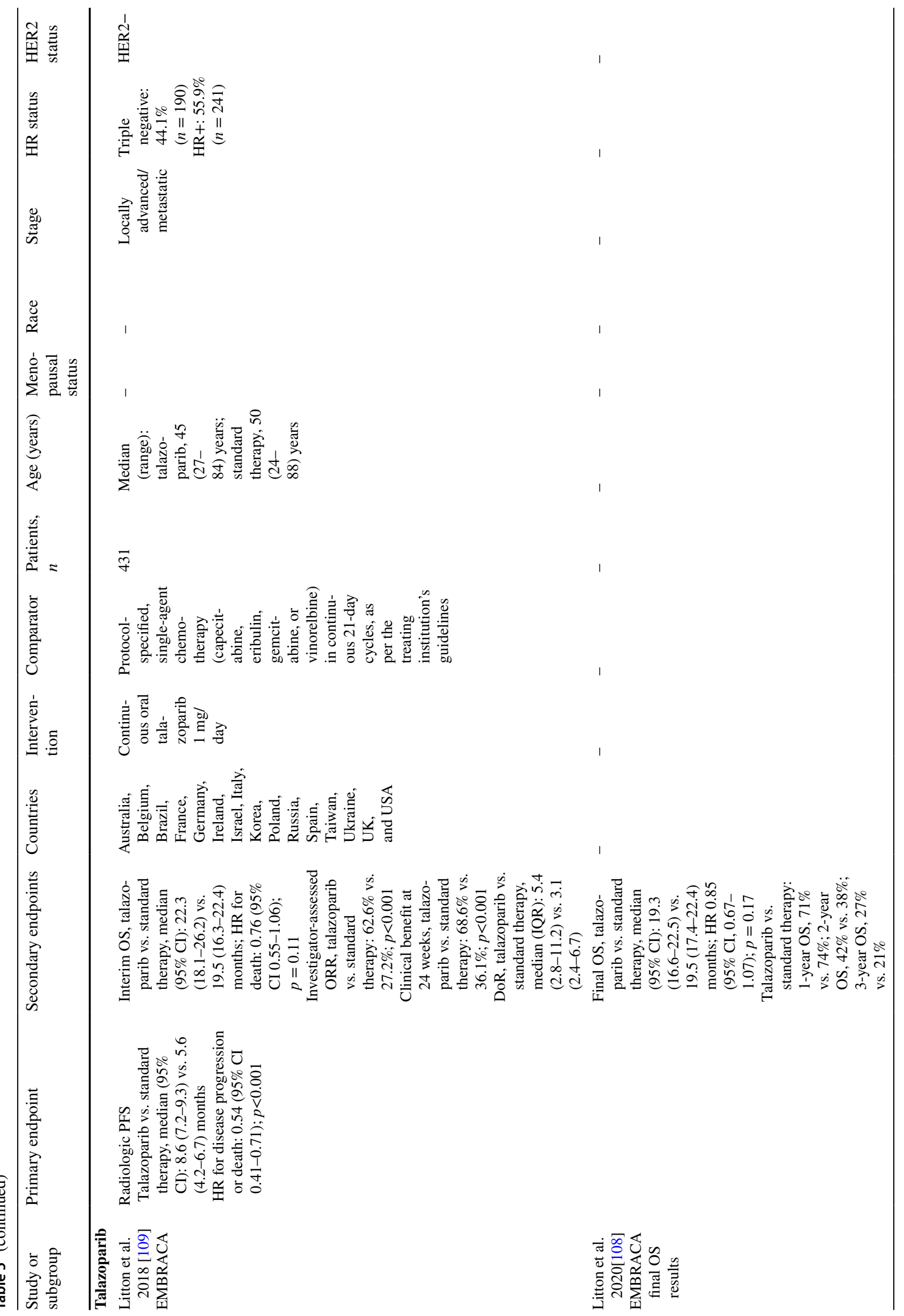




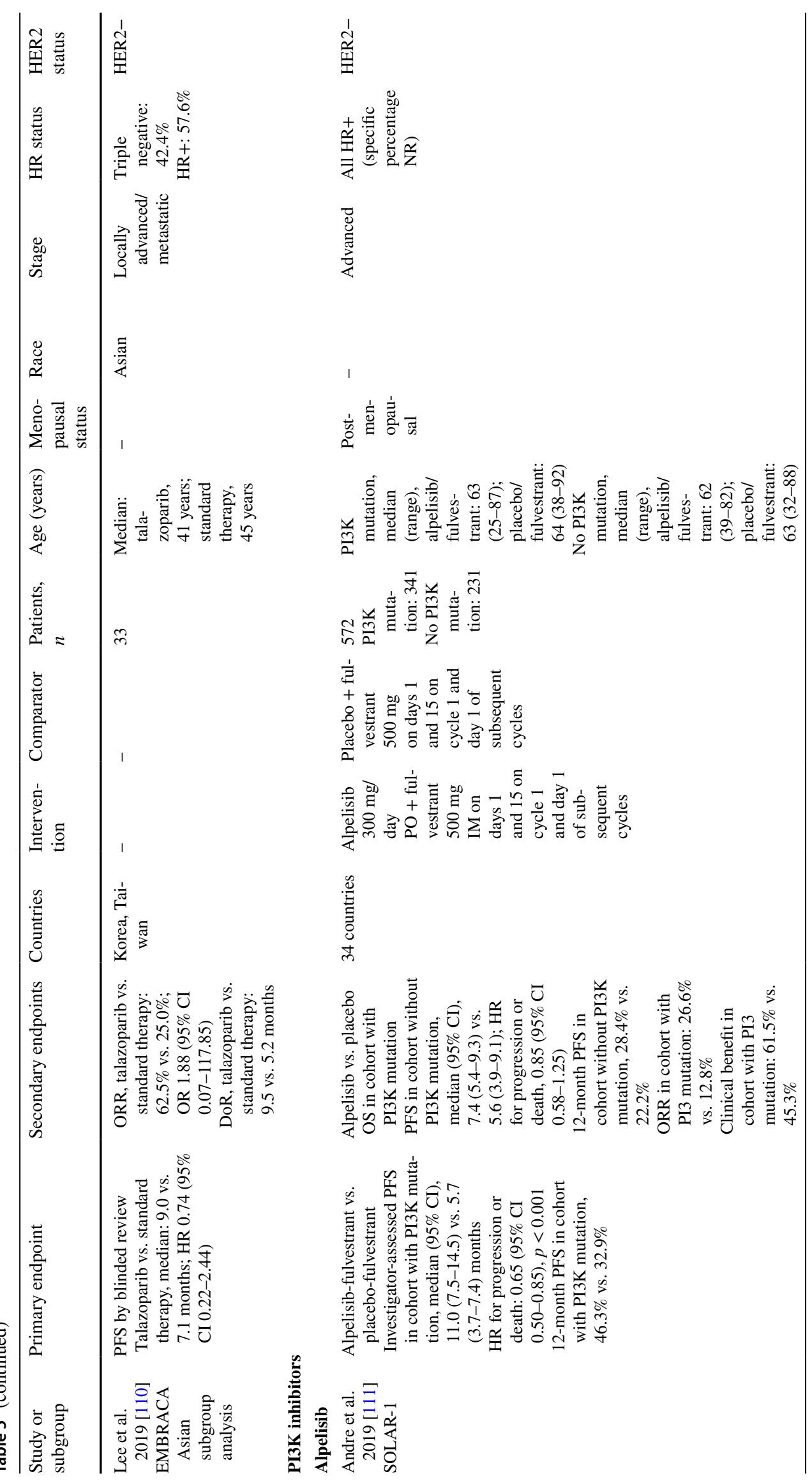




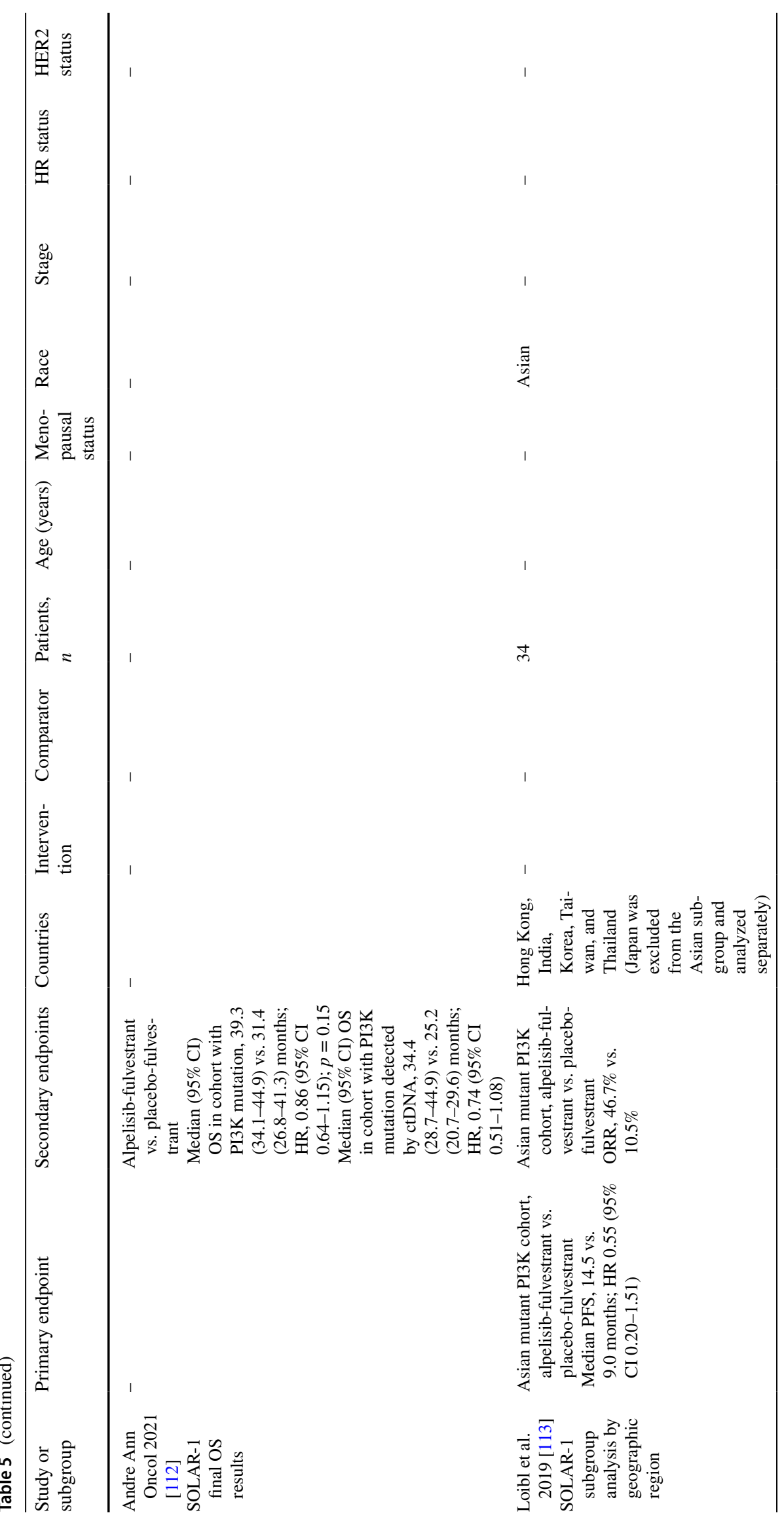




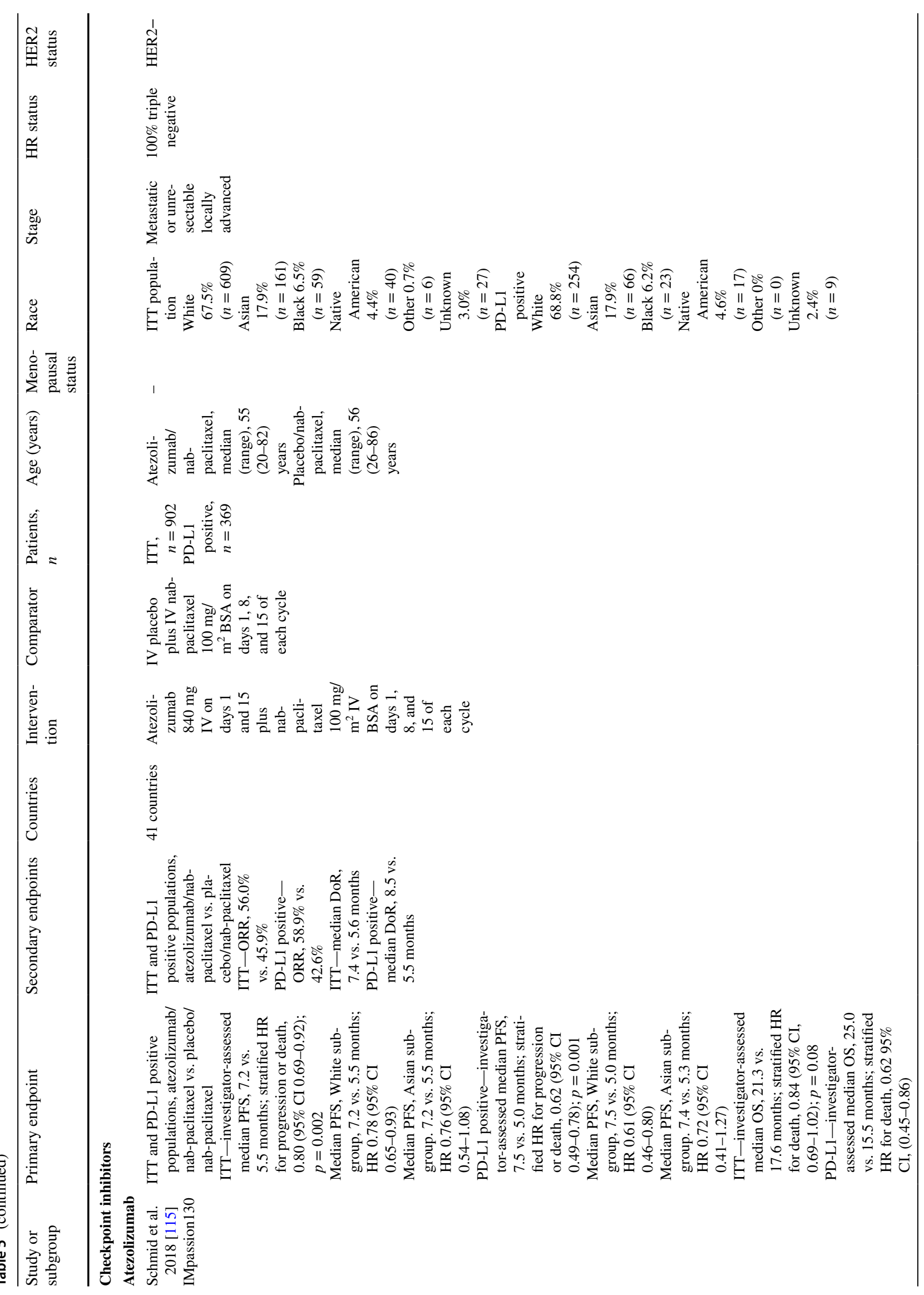




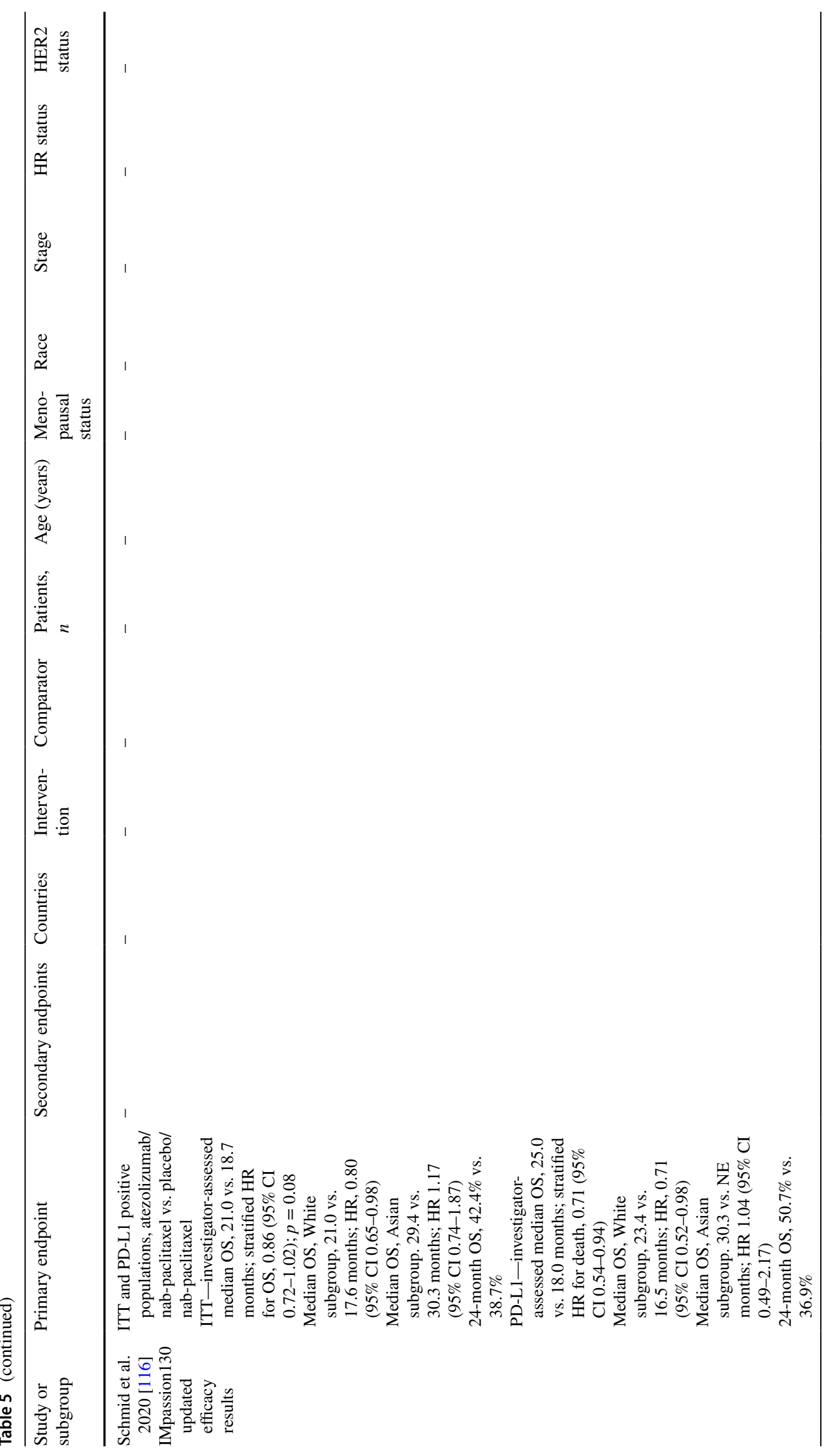




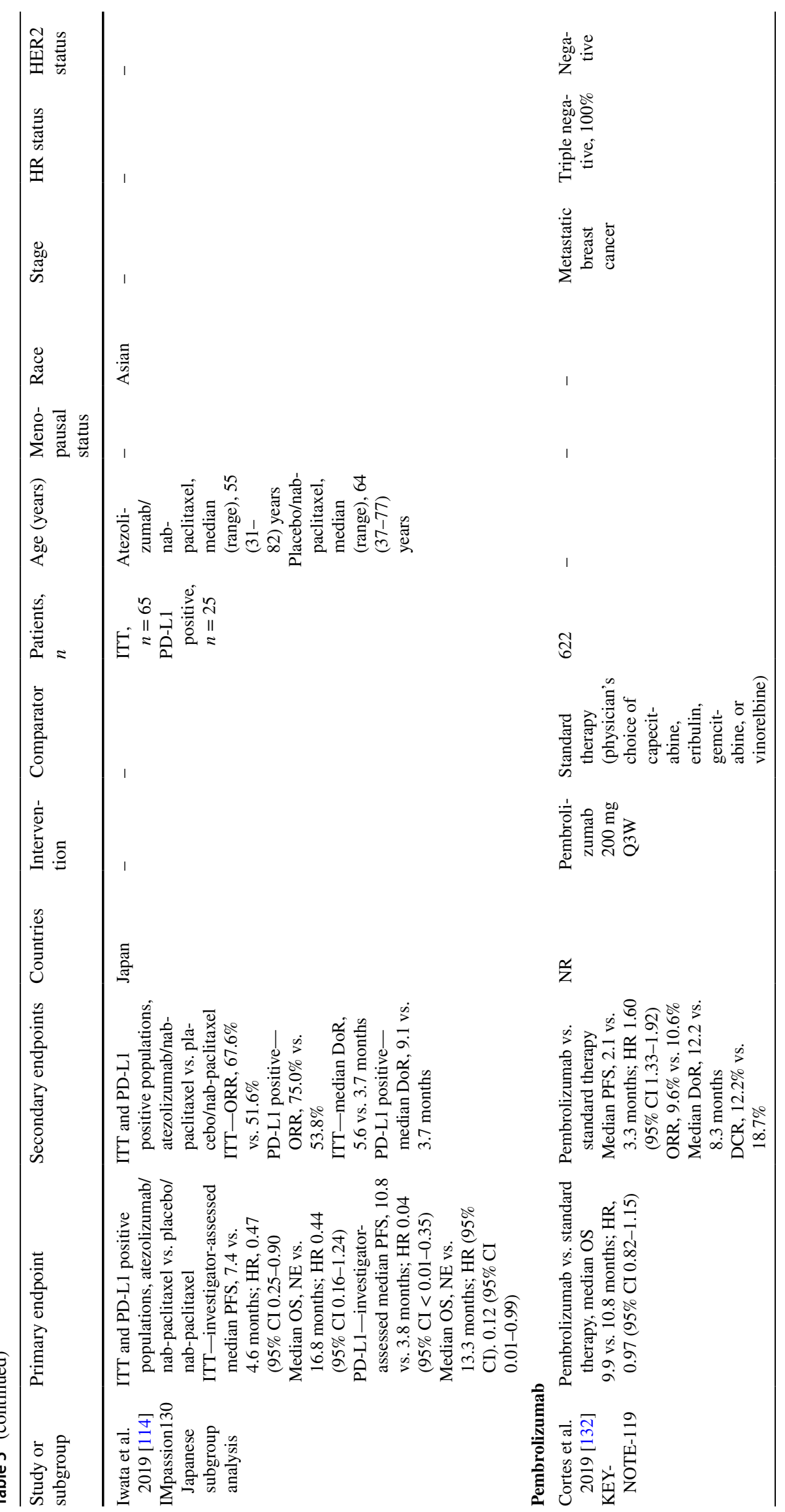




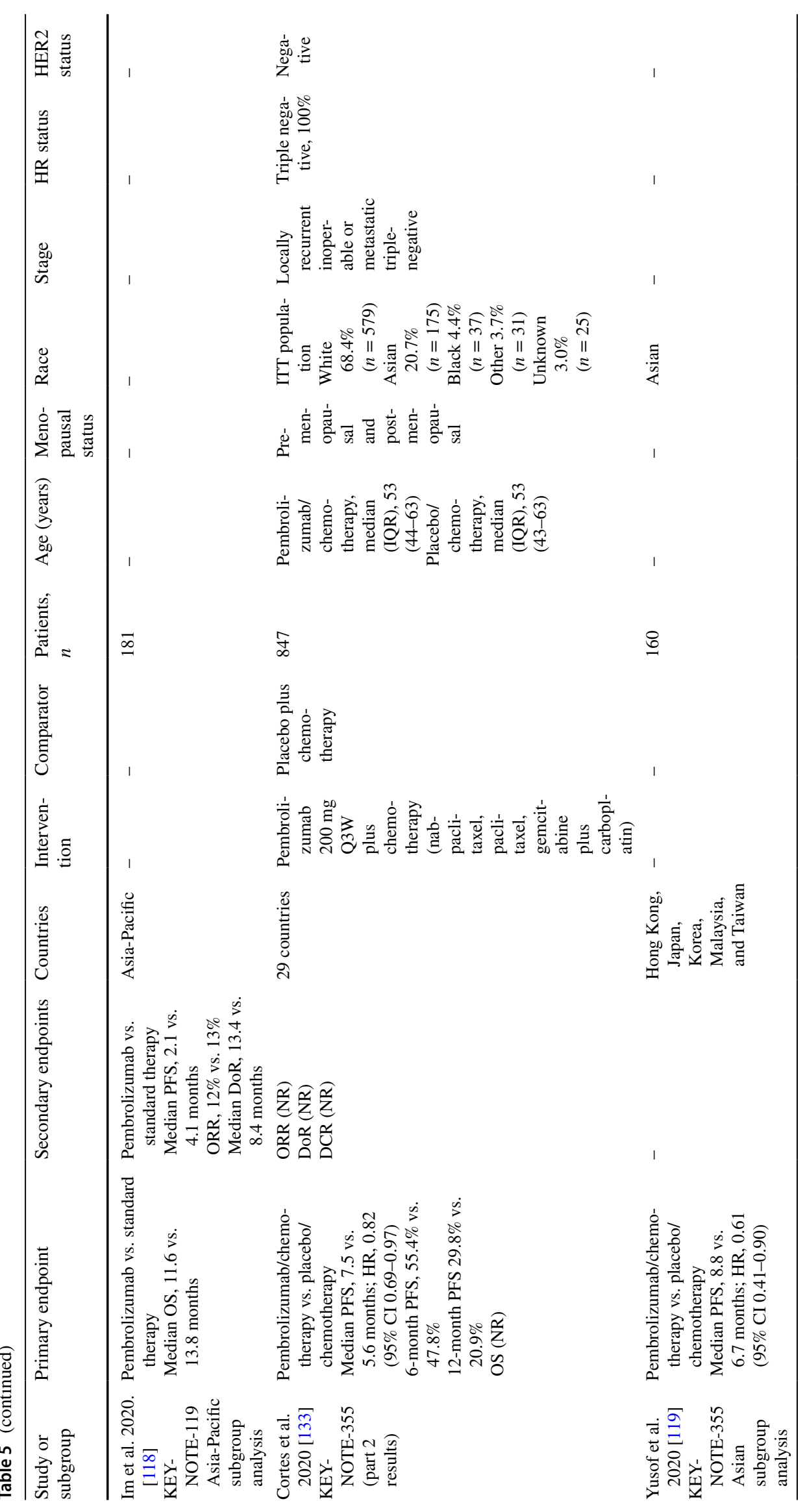




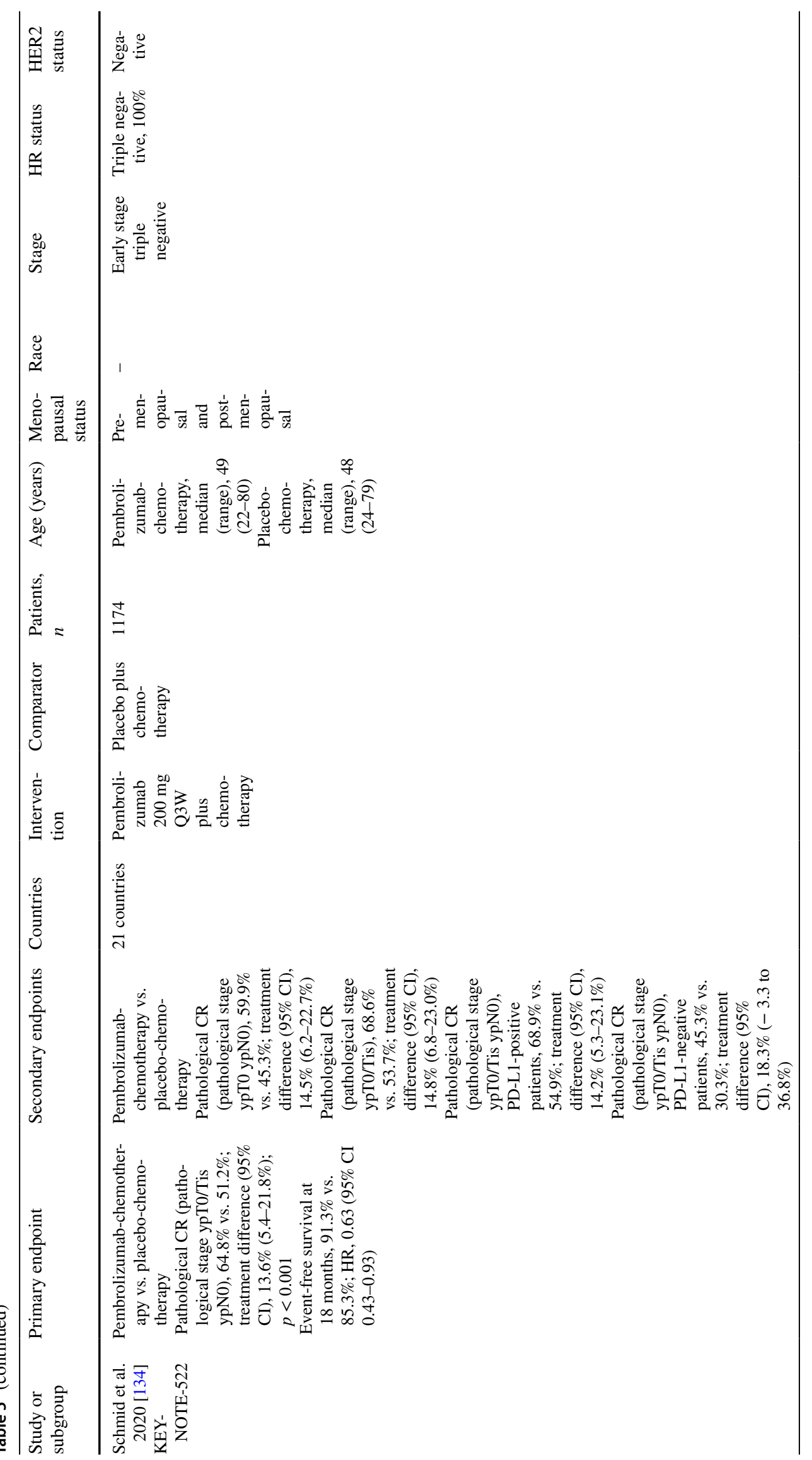




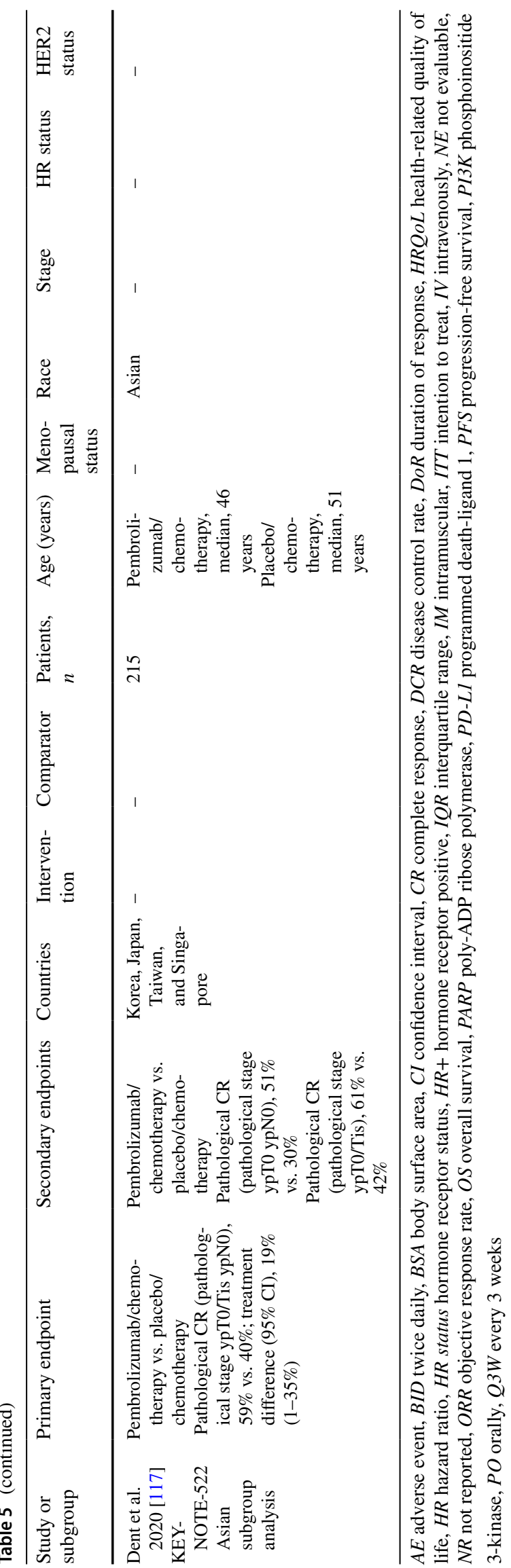

managed by dose adjustment, suggesting a pharmacokinetic mechanism.

Ethnic disparity has been ignored or meagerly addressed in the past, especially during the era of chemotherapies. With the emergence of evolving targeted agents, some evidence has shed light on ethnic differences in treatment response. This highlights the importance of considering ethnic differences in pharmacokinetics and pharmacodynamics when designing clinical trials of new therapies and it is expected that the greater insights into tumor and patient characteristics from future studies will help guide treatment selection for Asians. Combined with increased recruitment of Asians into clinical trials to facilitate robust subgroup analysis and ongoing pharmacovigilance reporting, incremental improvements in clinical outcomes for Asians with $\mathrm{BC}$ can be expected in the future.

Acknowledgements Editorial support was provided by Rangan Gupta, Eli Lilly Services India Private Limited. Sheridan Henness, PhD, of Rx Communications (Mold, UK), made revisions to later versions of the manuscript under the direction of the authors.

\section{Declarations}

Funding Funding for this article was provided by Eli Lilly and Company.

Conflict of interest Yen-Shen Lu reports grants and personal fees from Novartis, Pfizer, Roche, and Merck Sharp and Dohme. Winnie Yeo reports personal fees from advisory and speaker roles from Novartis, Eli Lilly and Company, AstraZeneca, Pfizer, Merck, and Eisai. YoonSim Yap reports personal fees and non-financial support from Roche, Eli Lilly and Company, Novartis, AstraZeneca, Pfizer, and Eisai. Yeon Hee Park reports grants and non-financial support from Pfizer, AstraZeneca, Novartis, Merck, Roche, and grants from Eisai. Rebecca Cheng reports personal fees from Eli Lilly and Company. Kenji Tamura and Huiping Li indicated no financial relationships.

Availability of data and material Not applicable.

Code availability Not applicable.

Author contributions Y-SL, RC, and HL contributed to the conception of the manuscript. Y-SL, Y-SY, RC, and HL contributed to the study design. Y-SL, HL, RC, and YHP contributed to data acquisition. Y-SL, WY, Y-SY, KT, RC, YHP, and HL contributed to data interpretation. RC, and KT drafted the manuscript. Y-SL, WY, Y-SY, KT, HL, RC, and YHP critically reviewed the manuscript. All authors approved the final submitted version.

Ethics approval Not applicable.

Current participants Not applicable.

Consent for publication Not applicable.

Open Access This article is licensed under a Creative Commons Attribution-NonCommercial 4.0 International License, which permits any non-commercial use, sharing, adaptation, distribution and reproduction in any medium or format, as long as you give appropriate credit to the 
original author(s) and the source, provide a link to the Creative Commons licence, and indicate if changes were made. The images or other third party material in this article are included in the article's Creative Commons licence, unless indicated otherwise in a credit line to the material. If material is not included in the article's Creative Commons licence and your intended use is not permitted by statutory regulation or exceeds the permitted use, you will need to obtain permission directly from the copyright holder. To view a copy of this licence, visit http://creativecommons.org/licenses/by-nc/4.0/.

\section{References}

1. Fan L, Goss PE, Strasser-Weippl K. Current status and future projections of breast cancer in Asia. Breast Care (Basel). 2015;10:372-8. https://doi.org/10.1159/000441818.

2. Hirabayashi Y, Zhang M. Comparison of time trends in breast cancer incidence (1973-2002) in Asia, from cancer incidence in five continents, Vols IV-IX. Jpn J Clin Oncol. 2009;39:411-2. https://doi.org/10.1093/jjco/hyp054.

3. Bhoo-Pathy N, Yip C-H, Hartman M, Uiterwaal CSPM, Devi BCR, Peeters PHM, et al. Breast cancer research in Asia: adopt or adapt Western knowledge? Eur J Cancer. 2013;49:703-9. https://doi.org/10.1016/j.ejca.2012.09.014.

4. Youlden DR, Cramb SM, Yip CH, Baade PD. Incidence and mortality of female breast cancer in the Asia-Pacific region. Cancer Biol Med. 2014;11:101-15. https://doi.org/10.7497/j.issn.20953941.2014.02.005.

5. Perry CS, Otero JC, Palmer JL, Gross AS. Risk factors for breast cancer in East Asian women relative to women in the West. Asia Pac J Clin Oncol. 2009;5:219-31. https://doi.org/10.1111/j.17437563.2009.01242.x.

6. Lin CH, Yap YS, Lee KH, Im SA, Naito Y, Yeo W, et al. Contrasting epidemiology and clinicopathology of female breast cancer in Asians versus the US population. J Natl Cancer Inst. 2019;111:1298-306. https://doi.org/10.1093/jnci/djz090.

7. Kan Z, Ding Y, Kim J, Jung HH, Chung W, Lal S, et al. Multiomics profiling of younger Asian breast cancers reveals distinctive molecular signatures. Nat Commun. 2018;9:1725. https:// doi.org/10.1038/s41467-018-04129-4.

8. Lin CH, Liau JY, Lu YS, Huang CS, Lee WC, Kuo KT, et al. Molecular subtypes of breast cancer emerging in young women in Taiwan: evidence for more than just westernization as a reason for the disease in Asia. Cancer Epidemiol Biomark Prev. 2009;18:1807-14. https://doi.org/10.1158/1055-9965. EPI-09-0096.

9. Lin $\mathrm{CH}$, Chuang PY, Chiang CJ, Lu YS, Cheng AL, Kuo $\mathrm{WH}$, et al. Distinct clinicopathological features and prognosis of emerging young-female breast cancer in an East Asian country: a nationwide cancer registry-based study. Oncologist. 2014;19:583-91. https://doi.org/10.1634/theoncologist. 2014-0047.

10. Kurebayashi J, Miyoshi Y, Ishikawa T, Saji S, Sugie T, Suzuki $\mathrm{T}$, et al. Clinicopathological characteristics of breast cancer and trends in the management of breast cancer patients in Japan: based on the Breast Cancer Registry of the Japanese Breast Cancer Society between 2004 and 2011. Breast Cancer. 2015;22:235-44. https://doi.org/10.1007/s12282-015-0599-6.

11. Xu B, Zhang XQ, Chi HD, Liu Z, Quinlivan M, Orlando M. Consistent efficacy and safety of gemcitabine-paclitaxel in patients with metastatic breast cancer: a retrospective comparison of East Asian and global studies. Asia Pac J Clin Oncol. 2014;10:330-9. https://doi.org/10.1111/ajco.12116.

12. O'Donnell PH, Dolan ME. Cancer pharmacoethnicity: ethnic differences in susceptibility to the effects of chemotherapy. Clin
Cancer Res. 2009;15:4806-14. https://doi.org/10.1158/10780432.CCR-09-0344.

13. Ogawara M, Kawahara M, Hosoe S, Atagi S, Kawaguchi T, Okishio K, et al. A feasibility study of paclitaxel $225 \mathrm{mg} / \mathrm{m}(2)$ and carboplatin AUC $=6$ in untreated advanced non-small cell lung cancer patients in Japan. Jpn J Clin Oncol. 2002;32:48-53. https://doi.org/10.1093/jjco/hyf014.

14. Takei Y, Suzuki M, Ohwada M, Saga Y, Kohno T, Machida S, et al. A feasibility study of paclitaxel and carboplatin therapy in Japanese patients with epithelial ovarian cancer. Oncol Rep. 2003;10:951-5.

15. Ling WH, Lee SC. Inter-ethnic differences-how important is it in cancer treatment? Ann Acad Med Singapore. 2011;40:356-61.

16. Chow LWC, Biganzoli L, Leo AD, Kuroi K, Han HS, Patel J, et al. Toxicity profile differences of adjuvant docetaxel/cyclophosphamide (TC) between Asian and Caucasian breast cancer patients. Asia Pac J Clin Oncol. 2017;13:372-8. https://doi.org/ 10.1111/ajco.12682.

17. Kim CG, Sohn J, Chon H, Kim JH, Heo SJ, Cho H, et al. Incidence of febrile neutropenia in Korean female breast cancer patients receiving preoperative or postoperative doxorubicin/ cyclophosphamide followed by docetaxel chemotherapy. J Breast Cancer. 2016;19:76-82. https://doi.org/10.4048/jbc.2016.19.1. 76.

18. Kenmotsu H, Tanigawara Y. Pharmacokinetics, dynamics and toxicity of docetaxel: why the Japanese dose differs from the Western dose. Cancer Sci. 2015;106:497-504. https://doi.org/ 10.1111/cas.12647.

19. Swain SM, Im YH, Im SA, Chan V, Miles D, Knott A, et al. Safety profile of pertuzumab with trastuzumab and docetaxel in patients from Asia with human epidermal growth factor receptor 2-positive metastatic breast cancer: results from the phase III trial CLEOPATRA. Oncologist. 2014;19:693-701. https://doi.org/10. 1634/theoncologist.2014-0033.

20. Ma B, Yeo W, Hui P, Ho WM, Johnson PJ. Acute toxicity of adjuvant doxorubicin and cyclophosphamide for early breast cancer-a retrospective review of Chinese patients and comparison with an historic Western series. Radiother Oncol. 2002;62:1859. https://doi.org/10.1016/s0167-8140(02)00003-8.

21. Chan A, Chen C, Chiang J, Tan SH, Ng R. Incidence of febrile neutropenia among early-stage breast cancer patients receiving anthracycline-based chemotherapy. Support Care Cancer. 2012;20:1525-32. https://doi.org/10.1007/s00520-011-1241-6.

22. Tokudome N, Ito Y, Hatake K, Toi M, Sano M, Iwata H, et al. Trastuzumab and vinorelbine as first-line therapy for HER2overexpressing metastatic breast cancer: multicenter phase II and pharmacokinetic study in Japan. Anticancer Drugs. 2008;19:753-9. https://doi.org/10.1097/CAD.0b013e3283 $02 \mathrm{eb} 15$.

23. Zhang L, Zimin S, Yongqian S, Zefei J, Jie W, Jean-Philippe B, et al. Oral vinorelbine (NVBo) in Asian advanced breast cancer and non small cell lung cancer (NSCLC) patients (pts): pharmacokinetics (PK) coupled with efficacy and safety as first line treatment—a Chinese experience. Eur J Cancer. 2015;51:S150. https://doi.org/10.1016/S0959-8049(16)30442-7.

24. Haller DG, Cassidy J, Clarke SJ, Cunningham D, Van Cutsem E, Hoff PM, et al. Potential regional differences for the tolerability profiles of fluoropyrimidines. J Clin Oncol. 2008;26:2118-23. https://doi.org/10.1200/JCO.2007.15.2090.

25. Yap YS, Lu YS, Tamura K, Lee JE, Ko EY, Park YH, et al. Insights into breast cancer in the East vs the West: a review. JAMA Oncol. 2019;5:1489-96. https://doi.org/10.1001/jamao ncol.2019.0620.

26. Zujewski JA, Rubinstein L. CREATE-X a role for capecitabine in early-stage breast cancer: an analysis of available 
data. NPJ Breast Cancer. 2017;3:27. https://doi.org/10.1038/ s41523-017-0029-3.

27. Reigner B, Watanabe T, Schuller J, Lucraft H, Sasaki Y, Bridgewater J, et al. Pharmacokinetics of capecitabine (Xeloda) in Japanese and Caucasian patients with breast cancer. Cancer Chemother Pharmacol. 2003;52:193-201. https://doi.org/10. 1007/s00280-003-0642-8.

28. Lv H, Yan M, Zhang M, Niu L, Zeng H, Cui S. Efficacy of capecitabine-based combination therapy and single-agent capecitabine maintenance therapy in patients with metastatic breast cancer. Chin J Cancer Res. 2014;26:692-7. https://doi. org/10.3978/j.issn.1000-9604.2014.12.13.

29. Araki K, Ishida N, Horii R, Takahashi S, Akiyama F, Ito Y, et al. Efficacy of fulvestrant $500 \mathrm{mg}$ in Japanese postmenopausal advanced/recurrent breast cancer patients and factors associated with prolonged time-to-treatment failure. Expert Opin Pharmacother. 2015;16:2561-8. https://doi.org/10.1517/14656566.2015. 1107042.

30. Di Leo A, Jerusalem G, Petruzelka L, Torres R, Bondarenko IN, Khasanov R, et al. Results of the CONFIRM phase III trial comparing fulvestrant $250 \mathrm{mg}$ with fulvestrant $500 \mathrm{mg}$ in postmenopausal women with estrogen receptor-positive advanced breast cancer. J Clin Oncol. 2010;28:4594-600. https://doi.org/ 10.1200/JCO.2010.28.8415.

31. Goss PE, Ingle JN, Martino S, Robert NJ, Muss HB, Piccart MJ, et al. A randomized trial of letrozole in postmenopausal women after five years of tamoxifen therapy for early-stage breast cancer. N Engl J Med. 2003;349:1793-802. https://doi.org/10.1056/ NEJMoa032312.

32. Han S, Lee SJ, Noh W, Nam S, Kang S, Kim J, et al. 299P Assessment of quality of life, BMD and safety profiles in postmenopausal breast cancer patients with letrozole as an early adjuvant treatment (KBCSG-008). Ann Oncol. 2014;25:iv100. https://doi.org/10.1093/annonc/mdu327.45.

33. Kiyotani K, Mushiroda T, Imamura CK, Hosono N, Tsunoda T, Kubo M, et al. Significant effect of polymorphisms in CYP2D6 and $\mathrm{ABCC} 2$ on clinical outcomes of adjuvant tamoxifen therapy for breast cancer patients. J Clin Oncol. 2010;28:1287-93. https://doi.org/10.1200/JCO.2009.25.7246.

34. Lim HS, Ju Lee H, Seok Lee K, Sook Lee E, Jang IJ, Ro J. Clinical implications of CYP2D6 genotypes predictive of tamoxifen pharmacokinetics in metastatic breast cancer. J Clin Oncol. 2007;25:3837-45. https://doi.org/10.1200/JCO.2007.11.4850.

35. Lu J, Li H, Guo P, Shen R, Luo Y, Ge Q, et al. The effect of CYP2D6 *10 polymorphism on adjuvant tamoxifen in Asian breast cancer patients: a meta-analysis. Onco Targets Ther. 2017;10:5429-37. https://doi.org/10.2147/OTT.S149197.

36. Moy B, Tu D, Pater JL, Ingle JN, Shepherd LE, Whelan TJ, et al. Clinical outcomes of ethnic minority women in MA.17: a trial of letrozole after 5 years of tamoxifen in postmenopausal women with early stage breast cancer. Ann Oncol. 2006;17:1637-43. https://doi.org/10.1093/annonc/mdl177.

37. Nishimura R, Anan K, Yamamoto Y, Higaki K, Tanaka M, Shibuta K, et al. Efficacy of goserelin plus anastrozole in premenopausal women with advanced or recurrent breast cancer refractory to an LH-RH analogue with tamoxifen: results of the JMTO BC08-01 phase II trial. Oncol Rep. 2013;29:1707-13. https://doi.org/10.3892/or.2013.2312.

38. Noguchi S, Ellis MJ, Robertson JFR, Thirlwell J, Fazal M, Shao Z. Progression-free survival results in postmenopausal Asian women: subgroup analysis from a phase III randomized trial of fulvestrant $500 \mathrm{mg}$ vs anastrozole $1 \mathrm{mg}$ for hormone receptorpositive advanced breast cancer (FALCON). Breast Cancer. 2018;25:356-64. https://doi.org/10.1007/s12282-018-0838-8.

39. Robertson JFR, Bondarenko IM, Trishkina E, Dvorkin M, Panasci L, Manikhas A, et al. Fulvestrant $500 \mathrm{mg}$ versus anastrozole $1 \mathrm{mg}$ for hormone receptor-positive advanced breast cancer (FALCON): an international, randomised, double-blind, phase 3 trial. Lancet. 2016;388:2997-3005. https://doi.org/10. 1016/S0140-6736(16)32389-3.

40. Shao X, Wang XJ, Zheng Y, Chen Z-H, Li G, Shi L, et al. Efficacy and safety of fulvestrant $500 \mathrm{mg}$ in Chinese HR-positive, HER2-negative metastatic breast cancer patients: a real-world study. J Clin Oncol. 2018;36:e13046-e13046. https://doi.org/10. 1200/JCO.2018.36.15_suppl.e13046.

41. Toss A, Berger A, Guiles F, Sendecki JA, Simone N, Anne PR, et al. 310P Preventive tamoxifen after ductal carcinoma in situ (Dcis) diagnosis according to age and ethnicity. Ann Oncol. 2014;25:iv103. https://doi.org/10.1093/annonc/mdu327.55.

42. Wu S, Li Q, Zhu Y, Sun J, Li F, Lin H, et al. Role of goserelin in combination with endocrine therapy for the treatment of advanced breast cancer in premenopausal women positive for hormone receptor: a retrospective matched case-control study. Cancer Biother Radiopharm. 2013;28:697-702. https://doi.org/ 10.1089/cbr.2012.1436.

43. Fabian C, Tilzer L, Sternson L. Comparative binding affinities of tamoxifen, 4-hydroxytamoxifen, and desmethyltamoxifen for estrogen receptors isolated from human breast carcinoma: correlation with blood levels in patients with metastatic breast cancer. Biopharm Drug Dispos. 1981;2:381-90. https://doi.org/10.1002/ bdd. 2510020407.

44. Desta Z, Ward BA, Soukhova NV, Flockhart DA. Comprehensive evaluation of tamoxifen sequential biotransformation by the human cytochrome $\mathrm{P} 450$ system in vitro: prominent roles for CYP3A and CYP2D6. J Pharmacol Exp Ther. 2004;310:106275. https://doi.org/10.1124/jpet.104.065607.

45. Klein DJ, Thorn CF, Desta Z, Flockhart DA, Altman RB, Klein TE. PharmGKB summary: tamoxifen pathway, pharmacokinetics. Pharmacogenet Genom. 2013;23:643-7. https://doi.org/10. 1097/FPC.0b013e3283656bc1.

46. Jung JA, Lim HS. Association between CYP2D6 genotypes and the clinical outcomes of adjuvant tamoxifen for breast cancer: a meta-analysis. Pharmacogenomics. 2014;15:49-60. https://doi. org/10.2217/pgs.13.221.

47. Baselga J, Cortes J, Kim SB, Im SA, Hegg R, Im YH, et al. Pertuzumab plus trastuzumab plus docetaxel for metastatic breast cancer. N Engl J Med. 2012;366:109-19. https://doi.org/10.1056/ NEJMoa1113216.

48. Cameron D, Casey M, Press M, Lindquist D, Pienkowski $\mathrm{T}$, Romieu CG, et al. A phase III randomized comparison of lapatinib plus capecitabine versus capecitabine alone in women with advanced breast cancer that has progressed on trastuzumab: updated efficacy and biomarker analyses. Breast Cancer Res Treat. 2008;112:533-43. https://doi.org/10.1007/ s10549-007-9885-0.

49. Chan A, Delaloge S, Holmes FA, Moy B, Iwata H, Harvey VJ, et al. Neratinib after trastuzumab-based adjuvant therapy in patients with HER2-positive breast cancer (ExteNET): a multicentre, randomised, double-blind, placebo-controlled, phase 3 trial. Lancet Oncol. 2016;17:367-77. https://doi.org/10.1016/ S1470-2045(15)00551-3.

50. Geyer CE, Forster J, Lindquist D, Chan S, Romieu CG, Pienkowski T, et al. Lapatinib plus capecitabine for HER2-positive advanced breast cancer. N Engl J Med. 2006;355:2733-43. https://doi.org/10.1056/NEJMoa064320.

51. Iwata H, Fujii H, Masuda N, Mukai H, Nishimura Y, Katsura K, et al. Efficacy, safety, pharmacokinetics and biomarker findings in patients with HER2-positive advanced or metastatic breast cancer treated with lapatinib in combination with capecitabine: results from 51 Japanese patients treated in a clinical study. Breast Cancer. 2015;22:192-200. https://doi.org/10.1007/ s12282-013-0475-1. 
52. Iwata H, Masuda N, Kim S-B, Inoue K, Rai Y, Fujita T, et al. Abstract P1-13-11: neratinib in the extended adjuvant treatment of patients from Asia with early-stage HER2+ breast cancer after trastuzumab-based therapy: exploratory analyses from the phase III ExteNET trial. Cancer Res. 2018;78:P1-13-11-P11-13-11. https://doi.org/10.1158/1538-7445.sabcs17-p1-13-11.

53. Xu B, Kim S-B, Inoue K, Shen Z-Z, Lee JR, Zhang B, et al. Abstract P5-21-17: efficacy, safety and tolerability of neratinibbased therapy in patients from Asia with metastatic HER2+ breast cancer and other solid tumors: a pooled analysis of 6 clinical trials. Cancer Res. 2018;78:P5-21-17-P25-21-17. https://doi. org/10.1158/1538-7445.sabcs17-p5-21-17.

54. Xu BH, Jiang ZF, Chua D, Shao ZM, Luo RC, Wang XJ, et al. Lapatinib plus capecitabine in treating HER2-positive advanced breast cancer: efficacy, safety, and biomarker results from Chinese patients. Chin J Cancer. 2011;30:327-35. https://doi.org/10. 5732/cjc.010.10507.

55. Modi S, Andre F, Krop IE, Saura C, Yamashita T, Kim S-B, et al. Trastuzumab deruxtecan for HER2-positive metastatic breast cancer: DESTINY-Breast01 subgroup analysis. J Clin Oncol. 2020;38:1036-1036. https://doi.org/10.1200/JCO.2020.38.15_ suppl.1036.

56. Chien HC, Kao Yang YH, Bai JP. Trastuzumab-related cardiotoxic effects in Taiwanese women: a nationwide cohort study. JAMA Oncol. 2016;2:1317-25. https://doi.org/10.1001/jamao ncol.2016.1269.

57. Li C, Wang B, Lu D, Jin JY, Gao Y, Matsunaga K, et al. Ethnic sensitivity assessment of the antibody-drug conjugate trastuzumab emtansine (T-DM1) in patients with HER2-positive locally advanced or metastatic breast cancer. Cancer Chemother Pharmacol. 2016;78:547-58. https://doi.org/10.1007/ s00280-016-3099-2.

58. Dieras V, Harbeck N, Joy AA, Gelmon K, Ettl J, Verma S, et al. Palbociclib with letrozole in postmenopausal women with ER+/ HER2 - advanced breast cancer: hematologic safety analysis of the randomized PALOMA-2 trial. Oncologist. 2019;24:1514-25. https://doi.org/10.1634/theoncologist.2019-0019.

59. Finn RS, Martin M, Rugo HS, Jones S, Im SA, Gelmon K, et al. Palbociclib and letrozole in advanced breast cancer. N Engl J Med. 2016;375:1925-36. https://doi.org/10.1056/NEJMoa1607 303.

60. Goetz MP, Toi M, Campone M, Sohn J, Paluch-Shimon S, Huober J, et al. MONARCH 3: abemaciclib as initial therapy for advanced breast cancer. J Clin Oncol. 2017;35:3638-46. https:// doi.org/10.1200/JCO.2017.75.6155.

61. Im S, Sohn J, Tripathy D. 390 Ribociclib (RIB) + non-steroidal aromatase inhibitor (NSAI) + goserelin in premenopausal Asian women with hormone-receptor-positive (HR+), HER2negative (HER2-) advanced breast cancer (ABC): results from the randomized phase III MONALEESA-7 study. Ann Oncol. 2018;29:ix13-20. https://doi.org/10.1093/annonc/mdy428.

62. Inoue K, Masuda N, Iwata H, Takahashi M, Ito Y, Miyoshi Y, et al. Japanese subpopulation analysis of MONARCH 2: phase 3 study of abemaciclib plus fulvestrant for treatment of hormone receptor-positive, human epidermal growth factor receptor 2-negative breast cancer that progressed on endocrine therapy. Breast Cancer. 2021. https://doi.org/10.1007/s12282-021-012398 (Epub ahead of print).

63. Iwata H, Im SA, Masuda N, Im YH, Inoue K, Rai Y, et al. PALOMA-3: phase III trial of fulvestrant with or without palbociclib in premenopausal and postmenopausal women with hormone receptor-positive, human epidermal growth factor receptor 2-negative metastatic breast cancer that progressed on prior endocrine therapy-safety and efficacy in Asian patients. J Glob Oncol. 2017;3:289-303. https://doi.org/10.1200/JGO.2016. 008318 .
64. Johnston S, Martin M, Di Leo A, Im SA, Awada A, Forrester T, et al. MONARCH 3 final PFS: a randomized study of abemaciclib as initial therapy for advanced breast cancer. NPJ Breast Cancer. 2019;5:5. https://doi.org/10.1038/s41523-018-0097-z.

65. Kim JH, Im SA, Sim SH, Bananis E, Huang X, Kim HS, et al. Palbociclib plus fulvestrant in Korean patients from PALOMA-3 with hormone receptor-positive/human epidermal growth factor receptor 2-negative advanced breast cancer. J Breast Cancer. 2021;24:97-105. https://doi.org/10.4048/jbc.2021.24.e13.

66. Masuda N, Inoue K, Nakamura R, Rai Y, Mukai H, Ohno S, et al. Palbociclib in combination with fulvestrant in patients with hormone receptor-positive, human epidermal growth factor receptor 2-negative advanced breast cancer: PALOMA-3 subgroup analysis of Japanese patients. Int J Clin Oncol. 2019;24:262-73. https://doi.org/10.1007/s10147-018-1359-3.

67. Mukai H, Shimizu C, Masuda N, Ohtani S, Ohno S, Takahashi M, et al. Palbociclib in combination with letrozole in patients with estrogen receptor-positive, human epidermal growth factor receptor 2-negative advanced breast cancer: PALOMA-2 subgroup analysis of Japanese patients. Int J Clin Oncol. 2019;4:274-87. https://doi.org/10.1007/s10147-018-1353-9.

68. Slamon DJ, Neven P, Chia S, Fasching PA, De Laurentiis M, Im SA, et al. Phase III randomized study of ribociclib and fulvestrant in hormone receptor-positive, human epidermal growth factor receptor 2-negative advanced breast cancer: MONALEESA-3. J Clin Oncol. 2018;36:2465-72. https://doi.org/10.1200/JCO. 2018.78.9909.

69. Sledge GW Jr, Toi M, Neven P, Sohn J, Inoue K, Pivot X, et al. The effect of abemaciclib plus fulvestrant on overall survival in hormone receptor-positive, ERBB2-negative breast cancer that progressed on endocrine therapy-MONARCH 2: a randomized clinical trial. JAMA Oncol. 2020;6:116-24. https://doi.org/10. 1001/jamaoncol.2019.4782.

70. Sledge GW Jr, Toi M, Neven P, Sohn J, Inoue K, Pivot X, et al. MONARCH 2: abemaciclib in combination with fulvestrant in women with $\mathrm{HR}+/ \mathrm{HER} 2$ - advanced breast cancer who had progressed while receiving endocrine therapy. J Clin Oncol. 2017;35:2875-84. https://doi.org/10.1200/JCO.2017.73.7585.

71. Toi M, Bourayou N, Llombart A, Sledge G, Huang C, Im Y-H, et al. 960 MONARCH 2: abemaciclib in combination with fulvestrant in Asian women with HR+, HER2- advanced breast cancer who progressed on endocrine therapy. Ann Oncol. 2017;28:x26-34. https://doi.org/10.1093/annonc/mdx654.

72. Toi M, Inoue K, Masuda N, Iwata H, Sohn J, Hae Park I, et al. Abemaciclib in combination with endocrine therapy for East Asian patients with HR+, HER2- advanced breast cancer: MONARCH 2 \& 3 trials. Cancer Sci. 2021;112:2381-92. https:// doi.org/10.1111/cas.14877.

73. Tokunaga E, Toi M, Takahashi M, et al. MONARCH 3: abemaciclib as initial therapy for East Asian patients with HR+, HER2 - advanced breast cancer. In: Paper presented at the 26th Annual Meeting of the Japanese Breast Cancer Society, Kyoto, Japan, 16-18 May; 2018.

74. Yap YS, Chen S-C, Jung KH, Lee KS, Sohn J-H, Kim JH, et al. LBA1 First-line ribociclib + letrozole in postmenopausal Asian women with hormone receptor-positive (HR+), human epidermal growth factor receptor 2-negative (HER2-) advanced breast cancer (ABC): a subgroup analysis from MONALEESA-2. Ann Oncol. 2016. https://doi.org/10.1093/annonc/mdw637.001.

75. Im SA, Lu YS, Bardia A, Harbeck N, Colleoni M, Franke F, et al. Overall survival with ribociclib plus endocrine therapy in breast cancer. N Engl J Med. 2019;381:307-16. https://doi.org/10.1056/ NEJMoa1903765.

76. Lee KWC, Lord S, Finn RS, Lim E, Martin A, Loi S, et al. The impact of ethnicity on efficacy and toxicity of cyclin D kinase 4/6 inhibitors in advanced breast cancer: a meta-analysis. Breast 
Cancer Res Treat. 2019;174:271-8. https://doi.org/10.1007/ s10549-018-5054-x.

77. Sledge GW Jr, Toi M, Neven P, Sohn J, Inoue K, Pivot X, et al. The effect of abemaciclib plus fulvestrant on overall survival in hormone receptor-positive, ERBB2-negative breast cancer that progressed on endocrine therapy-MONARCH 2: a randomized clinical trial. JAMA Oncol. 2019;6:116-24. https://doi.org/10. 1001/jamaoncol.2019.4782.

78. Turner NC, Slamon DJ, Ro J, Bondarenko I, Im SA, Masuda $\mathrm{N}$, et al. Overall survival with palbociclib and fulvestrant in advanced breast cancer. N Engl J Med. 2018;379:1926-36. https://doi.org/10.1056/NEJMoa1810527.

79. Slamon DJ, Neven P, Chia S, Fasching PA, De Laurentiis M, Im SA, et al. Overall survival with ribociclib plus fulvestrant in advanced breast cancer. N Engl J Med. 2020;382:514-24. https:// doi.org/10.1056/NEJMoa1911149.

80. Yap YS, Kim S, Chiu JWY, Lim E, Broom R, Liu Z, et al. 48PAbemaciclib combined with adjuvant endocrine therapy in patients from Asia with high risk early breast cancer: monarchE. Ann Oncol. 2021;32:S37-47. https://doi.org/10.1016/annonc/ annonc504.

81. Verma S, Bartlett CH, Schnell P, DeMichele AM, Loi S, Ro $\mathrm{J}$, et al. Palbociclib in combination with fulvestrant in women with hormone receptor-positive/HER2-negative advanced metastatic breast cancer: detailed safety analysis from a multicenter, randomized, placebo-controlled, phase iii study (PALOMA-3). Oncologist. 2016;21:1165-75. https://doi.org/10.1634/theon cologist.2016-0097.

82. Im SA, Mukai H, Park IH, Masuda N, Shimizu C, Kim SB, et al. Palbociclib plus letrozole as first-line therapy in postmenopausal Asian women with metastatic breast cancer: results from the phase III, randomized PALOMA-2 study. J Glob Oncol. 2019;5:1-19. https://doi.org/10.1200/JGO.18.00173.

83. Iwata H, Fletcher O, Liu Y, Umeyama Y, Zhang Z, Schnell P, et al. Association of drug-related polymorphisms with palbociclib-related neutropenia: pharmacogenetic analysis of PALOMA-2/-3 (P2/3). J Clin Oncol. 2019;37:1060-1060. https:// doi.org/10.1200/JCO.2019.37.15_suppl.1060.

84. Iwata H, Umeyama Y, Liu Y, Zhang Z, Schnell P, Mori Y, et al. Evaluation of the association of polymorphisms with palbociclib-induced neutropenia: pharmacogenetic analysis of PALOMA-2/-3. Oncologist. 2021. https://doi.org/10.1002/onco. 13811 (Epub ahead of print).

85. Zheng J, Yu Y, Durairaj C, Dieras V, Finn RS, Wang DD. Impact of dose reduction on efficacy: implications of exposure-response analysis of palbociclib. Target Oncol. 2021;16:69-76. https://doi. org/10.1007/s11523-020-00771-5.

86. Pinheiro L, Blake K, Januskiene J, Yue QY, Arlett P. Geographical variation in reporting interstitial lung disease as an adverse drug reaction: findings from an European Medicines Agency analysis of reports in EudraVigilance. Pharmacoepidemiol Drug Saf. 2016;25:705-12. https://doi.org/10.1002/pds.3998.

87. Furukawa H, Oka S, Shimada K, Tsuchiya N, Tohma S. Genetics of interstitial lung disease: Vol de nuit (night flight). Clin Med Insights Circ Respir Pulm Med. 2015;9:1-7. https://doi.org/10. 4137/CCRPM.S23283.

88. Diéras V, Mori A, Rugo HS, Finn RS, Harbeck N, Joy AA, et al. 291P PALOMA-2: neutropenia (NP) patterns in patients (Pts) with estrogen receptor-positive $(\mathrm{ER}+)$ /human epidermal growth factor receptor 2-negative (HER2-) first-line advanced breast cancer $(\mathrm{ABC})$ receiving palbociclib + letrozole $(\mathrm{P}+\mathrm{L})$. Ann Oncol. 2017;28:V96. https://doi.org/10.1093/annonc/mdx365. 054 .

89. Masuda N, Mukai H, Inoue K, Rai Y, Ohno S, Mori Y, et al. Neutropenia management with palbociclib in Japanese patients with advanced breast cancer. Breast Cancer. 2019;26:637-50. https://doi.org/10.1007/s12282-019-00970-7.

90. Yap YS, Chiu J, Ito Y, Ishikawa T, Aruga T, Kim SJ, et al. Ribociclib, a CDK 4/6 inhibitor, plus endocrine therapy in Asian women with advanced breast cancer. Cancer Sci. 2020;111:3313-26. https://doi.org/10.1111/cas.14554.

91. Doi T, Hewes B, Kakizume T, Tajima T, Ishikawa N, Yamada Y. Phase I study of single-agent ribociclib in Japanese patients with advanced solid tumors. Cancer Sci. 2018;109:193-8. https://doi. org/10.1111/cas.13428.

92. Hurvitz SA, Andre F, Jiang Z, Shao Z, Mano MS, Neciosup $\mathrm{SP}$, et al. Combination of everolimus with trastuzumab plus paclitaxel as first-line treatment for patients with HER2-positive advanced breast cancer (BOLERO-1): a phase 3, randomised, double-blind, multicentre trial. Lancet Oncol. 2015;16:816-29. https://doi.org/10.1016/S1470-2045(15)00051-0.

93. Noguchi S, Masuda N, Iwata H, Mukai H, Horiguchi J, Puttawibul $\mathrm{P}$, et al. Efficacy of everolimus with exemestane versus exemestane alone in Asian patients with HER2-negative, hormone-receptor-positive breast cancer in BOLERO-2. Breast Cancer. 2014;21:703-14. https://doi.org/10.1007/ s12282-013-0444-8.

94. Toi M, Shao Z, Hurvitz S, Tseng LM, Zhang Q, Shen K, et al. Efficacy and safety of everolimus in combination with trastuzumab and paclitaxel in Asian patients with HER2+ advanced breast cancer in BOLERO-1. Breast Cancer Res. 2017;19:47. https://doi.org/10.1186/s13058-017-0839-0.

95. Toyama T, Ridolfi A, Royce M, Cardoso F, Jeong J, Srimuninnimit V, et al. 920 Everolimus (EVE) + letrozole (LET) in Asian patients with estrogen receptor-positive $(\mathrm{ER}+)$, human epidermal growth factor receptor 2-negative (HER2-) advanced breast cancer $(\mathrm{ABC})$ : results of a subgroup analysis from the BOLERO-4 study. Ann Oncol. 2017;28:X31. https://doi.org/10. 1093/annonc/mdx654.

96. Li HP, Shao B, Wang J, Song GH, Di LJ, Liang X, et al. A retrospective study of efficacy and safety for everolimus in hormone-receptor positive advanced breast cancer. Oncol Prog. $2015 ; 13: 120-4$.

97. Yonemori K, Fujiwara Y, Minami H, Kitagawa K, Fujii H, Arai $\mathrm{T}$, et al. Phase 1 trial of denosumab safety, pharmacokinetics, and pharmacodynamics in Japanese women with breast cancerrelated bone metastases. Cancer Sci. 2008;99:1237-42. https:// doi.org/10.1111/j.1349-7006.2008.00803.x.

98. Takahashi S, Iwase T, Kohno N, Ishikawa T, Taguchi T, Takahashi M, et al. Efficacy of zoledronic acid in postmenopausal Japanese women with early breast cancer receiving adjuvant letrozole: 12-month results. Breast Cancer Res Treat. 2012;133:685-93. https://doi.org/10.1007/s10549-012-1973-0.

99. Biskup E, Cai F, Vetter M. Bone targeted therapies in advanced breast cancer. Swiss Med Wkly. 2017;147: w14440. https://doi. org/10.4414/smw.2017.14440.

100. Kohno N, Aogi K, Minami H, Nakamura S, Asaga T, Iino Y, et al. Zoledronic acid significantly reduces skeletal complications compared with placebo in Japanese women with bone metastases from breast cancer: a randomized, placebo-controlled trial. J Clin Oncol. 2005;23:3314-21. https://doi.org/10.1200/JCO.2005.05. 116.

101. Brufsky A, Harker WG, Beck JT, Carroll R, Tan-Chiu E, Seidler $\mathrm{C}$, et al. Zoledronic acid inhibits adjuvant letrozole-induced bone loss in postmenopausal women with early breast cancer. J Clin Oncol. 2007;25:829-36. https://doi.org/10.1200/JCO.2005.05. 3744.

102. Bundred NJ, Campbell ID, Davidson N, DeBoer RH, Eidtmann $\mathrm{H}$, Monnier A, et al. Effective inhibition of aromatase inhibitor-associated bone loss by zoledronic acid in postmenopausal women with early breast cancer receiving adjuvant letrozole: 
ZO-FAST study results. Cancer. 2008;112:1001-10. https://doi. org/10.1002/cncr.23259.

103. Gnant M, Pfeiler G, Dubsky PC, Hubalek M, Greil R, Jakesz R, et al. Adjuvant denosumab in breast cancer (ABCSG-18): a multicentre, randomised, double-blind, placebo-controlled trial. Lancet. 2015;386:433-43. https://doi.org/10.1016/S0140-6736(15) 60995-3.

104. Stopeck AT, Lipton A, Body JJ, Steger GG, Tonkin K, de Boer RH, et al. Denosumab compared with zoledronic acid for the treatment of bone metastases in patients with advanced breast cancer: a randomized, double-blind study. J Clin Oncol. 2010;28:5132-9. https://doi.org/10.1200/JCO.2010.29.7101.

105. Robson M, Im SA, Senkus E, Xu B, Domchek SM, Masuda N, et al. Olaparib for metastatic breast cancer in patients with a germline BRCA mutation. N Engl J Med. 2017;377:523-33. https:// doi.org/10.1056/NEJMoa1706450.

106. Im SA, Xu B, Li W, Robson M, Ouyang Q, Yeh DC, et al. Olaparib monotherapy for Asian patients with a germline BRCA mutation and HER2-negative metastatic breast cancer: OlympiAD randomized trial subgroup analysis. Sci Rep. 2020;10:8753. https://doi.org/10.1038/s41598-020-63033-4.

107. Robson ME, Tung N, Conte P, Im SA, Senkus E, Xu B, et al. OlympiAD final overall survival and tolerability results: olaparib versus chemotherapy treatment of physician's choice in patients with a germline BRCA mutation and HER2-negative metastatic breast cancer. Ann Oncol. 2019;30:558-66. https://doi.org/10. 1093/annonc/mdz012.

108. Litton JK, Hurvitz SA, Mina LA, Rugo HS, Lee KH, Gonçalves A, et al. Talazoparib versus chemotherapy in patients with germline BRCA1/2-mutated HER2-negative advanced breast cancer: final overall survival results from the EMBRACA trial. Ann Oncol. 2020;31:1526-35. https://doi.org/10.1016/j.annonc.2020. 08.2098.

109. Litton JK, Rugo HS, Ettl J, Hurvitz SA, Gonçalves A, Lee KH, et al. Talazoparib in patients with advanced breast cancer and a germline BRCA mutation. N Engl J Med. 2018;379:753-63. https://doi.org/10.1056/NEJMoa1802905.

110. Lee K-H, Kim S-B, Sohn J, Goodwin A, Usari T, Lanzalone S, et al. Talazoparib (TALA) vs physician's choice of chemotherapy (PCT) in Asian patients (Pts) with HER2- advanced breast cancer $(\mathrm{ABC})$ and a germline BRCA1/2 mutation (gBRCA1/2mut): data from phase III EMBRACA. Ann Oncol. 2019;30:IX14. https://doi.org/10.1093/annonc/mdz418.001.

111. André F, Ciruelos E, Rubovszky G, Campone M, Loibl S, Rugo HS, et al. Alpelisib for PIK3CA-mutated, hormone receptor-positive advanced breast cancer. N Engl J Med. 2019;380:1929-40. https://doi.org/10.1056/NEJMoa1813904.

112. André F, Ciruelos EM, Juric D, Loibl S, Campone M, Mayer IA, et al. Alpelisib plus fulvestrant for PIK3CA-mutated, hormone receptor-positive, human epidermal growth factor receptor2-negative advanced breast cancer: final overall survival results from SOLAR-1. Ann Oncol. 2021;32:208-17. https://doi.org/10. 1016/j.annonc.2020.11.011.

113. Loibl S, Conte P, Campone M, Mayer I, Lu Y-S, Denduluri N, et al. Response rate by geographic region in patients with hormone receptor-positive, human epidermal growth factor receptor-2-negative advanced breast cancer from the SOLAR-1 trial. Ann Oncol. 2019;30:iii47-64.

114. Iwata H, Inoue K, Kaneko K, Ito Y, Tsugawa K, Hasegawa A, et al. Subgroup analysis of Japanese patients in a Phase 3 study of atezolizumab in advanced triple-negative breast cancer (IMpassion130). Jpn J Clin Oncol. 2019;49:1083-91. https://doi.org/10. 1093/jjco/hyz135.

115. Schmid P, Adams S, Rugo HS, Schneeweiss A, Barrios CH, Iwata $\mathrm{H}$, et al. Atezolizumab and nab-paclitaxel in advanced triple-negative breast cancer. N Engl J Med. 2018;379:2108-21. https://doi.org/10.1056/NEJMoa1809615.

116. Schmid P, Rugo HS, Adams S, Schneeweiss A, Barrios CH, Iwata $\mathrm{H}$, et al. Atezolizumab plus nab-paclitaxel as first-line treatment for unresectable, locally advanced or metastatic triplenegative breast cancer (IMpassion130): updated efficacy results from a randomised, double-blind, placebo-controlled, phase 3 trial. Lancet Oncol. 2020;21:44-59. https://doi.org/10.1016/ s1470-2045(19)30689-8.

117. Dent R, Cortes J, Pusztai L, McArthur HL, Kuemmel S, Bergh J, et al. 1O-KEYNOTE-522 Asian subgroup: phase III study of neoadjuvant pembrolizumab (pembro) vs placebo (pbo) + chemotherapy (chemo) followed by adjuvant pembro vs pbo for early triple-negative breast cancer (TNBC). Ann Oncol. 2020;31:S1241-54.

118. Im S, Cortes J, Lipatov O, Goncalves A, Lee K, Schmid P, et al. 440-Pembrolizumab (pembro) vs chemotherapy (chemo) for previously treated metastatic triple-negative breast cancer (mTNBC): KEYNOTE-119 Asia-Pacific subpopulation. Ann Oncol. 2020;31:S1257-69.

119. Md Yusof M, Cescon DW, Rugo HS, Im S, Gallardo C, Lipatov O, et al. 43O-Phase III KEYNOTE-355 study of pembrolizumab (pembro) vs placebo (pbo) + chemotherapy (chemo) for previously untreated locally recurrent inoperable or metastatic triple-negative breast cancer (TNBC): results for patients (Pts) enrolled in Asia. Ann Oncol. 2020;31:S1257-69.

120. Fernandes LL, Fashoyin-Aje LA, Sridhara R, Keegan P, Pazdur R. Enrollment of racial/ethnic minority patients in ovarian and breast cancer trials: an FDA analysis. J Clin Oncol. 2018;36:e18671-e18671. https://doi.org/10.1200/JCO.2018.36. 15_suppl.e18671.

121. Tanimoto T. A perspective on the benefit-risk assessment for new and emerging pharmaceuticals in Japan. Drug Des Dev Ther. 2015;9:1877-88. https://doi.org/10.2147/DDDT.S62636.

122. Roederer MW, McLeod HL. Applying the genome to national drug formulary policy in the developing world. Pharmacogenomics. 2010;11:633-6. https://doi.org/10.2217/pgs.10.55.

123. Wheeler SB, Reeder-Hayes KE, Carey LA. Disparities in breast cancer treatment and outcomes: biological, social, and health system determinants and opportunities for research. Oncologist. 2013;18:986-93. https://doi.org/10.1634/theoncologist. 2013-0243.

124. Smith CE, Fullerton SM, Dookeran KA, Hampel H, Tin A, Maruthur NM, et al. Using genetic technologies to reduce, rather than widen, health disparities. Health Aff (Millwood). 2016;35:1367-73. https://doi.org/10.1377/hlthaff.2015.1476.

125. Ahmed KA, Grass GD, Orman AG, Liveringhouse C, Montejo $\mathrm{ME}$, Soliman $\mathrm{HH}$, et al. Personalizing radiation treatment delivery in the management of breast cancer. Int J Breast Cancer. 2018;2018:6729802. https://doi.org/10.1155/2018/6729802.

126. Dowsett M, Donaldson K, Tsuboi M, Wong J, Yates R. Effects of the aromatase inhibitor anastrozole on serum oestrogens in Japanese and Caucasian women. Cancer Chemother Pharmacol. 2000;46:35-9. https://doi.org/10.1007/s002800000113.

127. Nomura Y, Koyama H, Ohashi Y, Watanabe H. Clinical dosage determination of a new aromatase inhibitor, anastrozole, in postmenopausal Japanese women with advanced breast cancer. Clin Drug Investig. 2000;20:357-69. https://doi.org/10.2165/00044 011-200020050-00007.

128. He DX, Ma X. Clinical utility of letrozole in the treatment of breast cancer: a Chinese perspective. Onco Targets Ther. 2016;9:1077-84. https://doi.org/10.2147/OTT.S81087.

129. Fujiwara Y, Tamura K, Kondo S, Tanabe Y, Iwasa S, Shimomura A, et al. Phase 1 study of abemaciclib, an inhibitor of CDK 4 and 6 , as a single agent for Japanese patients with advanced cancer. 
Cancer Chemother Pharmacol. 2016;78:281-8. https://doi.org/ 10.1007/s00280-016-3085-8.

130. Chan A, Moy B, Mansi J, Ejlertsen B, Holmes FA, Chia S, et al. Final efficacy results of neratinib in HER2-positive hormone receptor-positive early-stage breast cancer from the phase III ExteNET trial. Clin Breast Cancer. 2021;21(80-91): e87. https:// doi.org/10.1016/j.clbc.2020.09.014.

131. Iwata H, Masuda N, Kim SB, Inoue K, Rai Y, Fujita T, et al. Neratinib after trastuzumab-based adjuvant therapy in patients from Asia with early stage HER2-positive breast cancer. Future Oncol. 2019;15:2489-501. https://doi.org/10.2217/fon-2019-0143.

132. Cortés J, Lipatov O, Im SA, Gonçalves A, Lee KS, Schmid P, et al. LBA21-KEYNOTE-119: phase III study of pembrolizumab (pembro) versus single-agent chemotherapy (chemo) for metastatic triple negative breast cancer (mTNBC). Ann Oncol. 2019;30:v859-60. https://doi.org/10.1093/annonc/mdz394.010.

133. Cortes J, Cescon DW, Rugo HS, Nowecki Z, Im SA, Yusof MM, et al. Pembrolizumab plus chemotherapy versus placebo plus chemotherapy for previously untreated locally recurrent inoperable or metastatic triple-negative breast cancer (KEYNOTE-355): a randomised, placebo-controlled, double-blind, phase 3 clinical trial. Lancet. 2020;396:1817-28. https://doi.org/10.1016/s01406736(20)32531-9.

134. Schmid P, Cortes J, Pusztai L, McArthur H, Kümmel S, Bergh $\mathrm{J}$, et al. Pembrolizumab for early triple-negative breast cancer. N Engl J Med. 2020;382:810-21. https://doi.org/10.1056/NEJMo a1910549. 